\title{
Endocranial morphology of the extinct Antillean shrew Nesophontes (Lipotyphla: Nesophontidae) from natural and digital endocasts of Cuban taxa
}

\author{
Johanset Orihuela
}

\begin{abstract}
This paper describes the endocranial morphology of the extinct genus of Antillean shrews Nesophontes, based on natural and digital endocranial casts extracted from Cuban species. The endocranial casts show developed olfactory lobes without accessory bulbs, an exposed tectum with visible superior colliculi, a large cerebellum and vermis, and a smooth neocortex. Body mass was estimated from skull size to be between 97 and $114 \mathrm{~g}$, yielding encephalization quotients between 0.33 and 0.57 . Endocranial casts of Nesophontes are morphologically similar to those of Solenodon more so than to other lipotyphlans such as Sorex, Blarina, Erinaceus, or the afroinsectivoran Tenrec. The morphological similarity to Solenodon, not only in endocranial structures but also in the rest of the skeleton suggests a behavioral analogy between the two genera. The marked superior colliculi, prominent olfactory lobes, and facial musculoskeletal anatomy suggest that Nesophontes was most likely nocturnal and fossorial, relying on hearing, smell, and tactility to forage. Future analysis of the appendicular skeleton can help determine if this genus was solely terrestrial or if it also exploited arboreal habitats. All these morphologies can help elucidate Nesophontes's behavior, ecology, and the osteological variation that is observed in the genus.
\end{abstract}

Johanset Orihuela. Department of Earth and Environment (Geosciences), Florida International University, Miami, Florida 33199, USA, Paleonycteris@gmail.com

Keywords: Brain; Endocasts; Fossils; Cuban; Nesophontes; Antillean; Extinct; Shrew

\section{INTRODUCTION}

Nesophontidae (Anthony, 1916) and Solenodontidae (Gill, 1872) are so far the only two families of insectivorans known from the Antilles, of which only solenodons remain extant. Nesophon- tes has been extinct since the late Holocene, but has left a rich fossil record in the Greater Antilles (Morgan and Wood, 1986; MacPhee et al., 1999; Whidden and Asher, 2001; Hutterer, 2005; SilvaTaboada et al., 2007). Most recent phylogenetic

PE Article Number: 17.2.22A

Copyright: Palaeontological Association May 2014

Submission: 6 January 2013. Acceptance: 27 March 2014

Orihuela, Johanset. 2014. Endocranial morphology of the extinct Antillean shrew Nesophontes (Lipotyphla: Nesophontidae) from natural and digital endocasts of Cuban taxa. Palaeontologia Electronica Vol. 17, Issue 2;22A; 12p;

palaeo-electronica.org/content/2014/760-endocast-of-cuban-nesophontes 
data suggests that Nesophontidae and Solenodontidae are sister taxa to a clade of Holartic insectivorans that predate the $\mathrm{K} / \mathrm{T}$ event which include moles, hedgehogs, and shrews (Roca et al., 2004; Asher et al., 2005; Douady and Douzery, 2009). MacPhee and Grimaldi (1996) reported Nesophontes-size lipotyphlan remains from late Oligocene/ early Miocene amber from the Dominican Republic, in the Greater Antilles, but its classification remains uncertain. These ancient mammals are important to the understanding of Antillean land mammal biogeography and to discussions about insectivoran evolution (MacFadden, 1980; Asher et al., 2003, 2005; MacPhee, 2005).

Endocranial casts are relevant in the study of mammalian brains, and the evolution of endocranial morphology (Radinsky, 1968; Kielan-Jaworowska, 1984; Macrini et al., 2007a and b; Rowe et al., 2011; Silcox et al., 2011; Orliac et al., 2012). Endocranial casts do not represent actual brains. Instead, endocasts are impressions of external brain structures such as vessels and meninges (Bauchot and Stephan, 1967; Kielan-Jaworowska and Lancaster, 2004). Nevertheless, endocranial casts provide a unique opportunity for paleobiologists and paleoneurologists to study casts of soft tissue structures that are rarely preserved during fossilization. Particularly, endocasts allow investigators to infer the function, evolution, and behavior of extinct animals (Edinger, 1949; Clark, 1959; Eisenberg, 1981; Stephan et al., 1991; Jerison, 2009). Natural and digital endocasts have provided fundamental evidence of the neuroanatomy and behavior of primitive lineages such as multituberculates and insectivore-grade mammals, among other taxa, as a key to understanding mammalian evolution (Kielan-Jaworowska, 1984, 2004; Thewissen and Gingerich, 1989; Macrini et al., 2007a; Rowe, 1996; Rowe et al., 2011).

This paper reports the endocranial morphology of Nesophontes through the analysis of natural and digital endocranial casts. Although Nesophontes is known from well-preserved cranial specimens, their endocranial casts remained unreported and their morphology unstudied. The cranial osteology of Nesophontes has often been described in combination with that of Solenodon, with the most extensive treatments being those of Anthony (1916, 1918), McDowell (1958), MacPhee (1981, 2005), and Wible (2008). Other researchers have analyzed different features of nesophontid cranial morphology through the study of fossil crania, but not from endocranial casts (e.g., Gould and Garwood, 1969; Silva-Taboada et al., 2007). Through the analysis of Nesophontes endocranial casts this research describes and illustrates their endocranial morphology for the first time. Additionally, this manuscript explains the sensorial and behavioral characteristics from Nesophontes's neuromorphology, and compares it to that of Solenodon and other extant and extinct mammals. Such data provides basic information to evolutionary neurologists interested in mammalian or insectivoran neuroanatomy. Evolutionary signals and developmental drives (i.e., stages of brain evolution) lie outside the scope of this research. Nevertheless, the data presented here further enhance our knowledge and understanding of nesophontid systematics, paleoecology, and behavior.

\section{MATERIALS AND METHODS}

\section{Locality}

The specimens used in this study were extracted from a late Quaternary owl pellet deposit in Nesophontes Cave, Palenque Hill in northwestern Cuba. Specimens were excavated from a 50 $\mathrm{cm} \times 50 \mathrm{~cm} \times 50 \mathrm{~cm}$ test pit under the main doline (sinkhole). The association of the Nesophontes specimens with introduced rats (Rattus sp.) suggests a late Holocene age for the deposit (MacPhee et al., 1999). The cave's faunally-rich assemblage will be described elsewhere. All specimens are deposited in the National Museum of Natural History (MNHNCu), Havana, Cuba (uncataloged). The numbers referred to here are field numbers.

\section{Methodology}

This study is based on eight incomplete natural endocranial casts and four digital reconstructions from four nearly complete skulls (Figures 1, 2, $3,4,5,6$, and 7). The analyses included the Cuban species Nesophontes major and Nesophontes micrus. All measurements are given in Table 1.

Natural endocasts (Steinkerns) were extracted from two nearly complete adult skulls; one Nesophontes major (C181) and one Nesophontes micrus (C145) (Figure 1.1). The maturity of the specimens was assessed from tooth wear and cranial sutures (McDowell, 1958). The natural endocasts were extracted through partial destructive sampling of the braincase after the specimens were x-rayed (Figure 1.2-3). Skulls with cemented sediment inside the endocranial cavity were specially selected. The posterior portion of the braincase was then carefully removed and the natural endocasts carefully extracted. These endocasts 

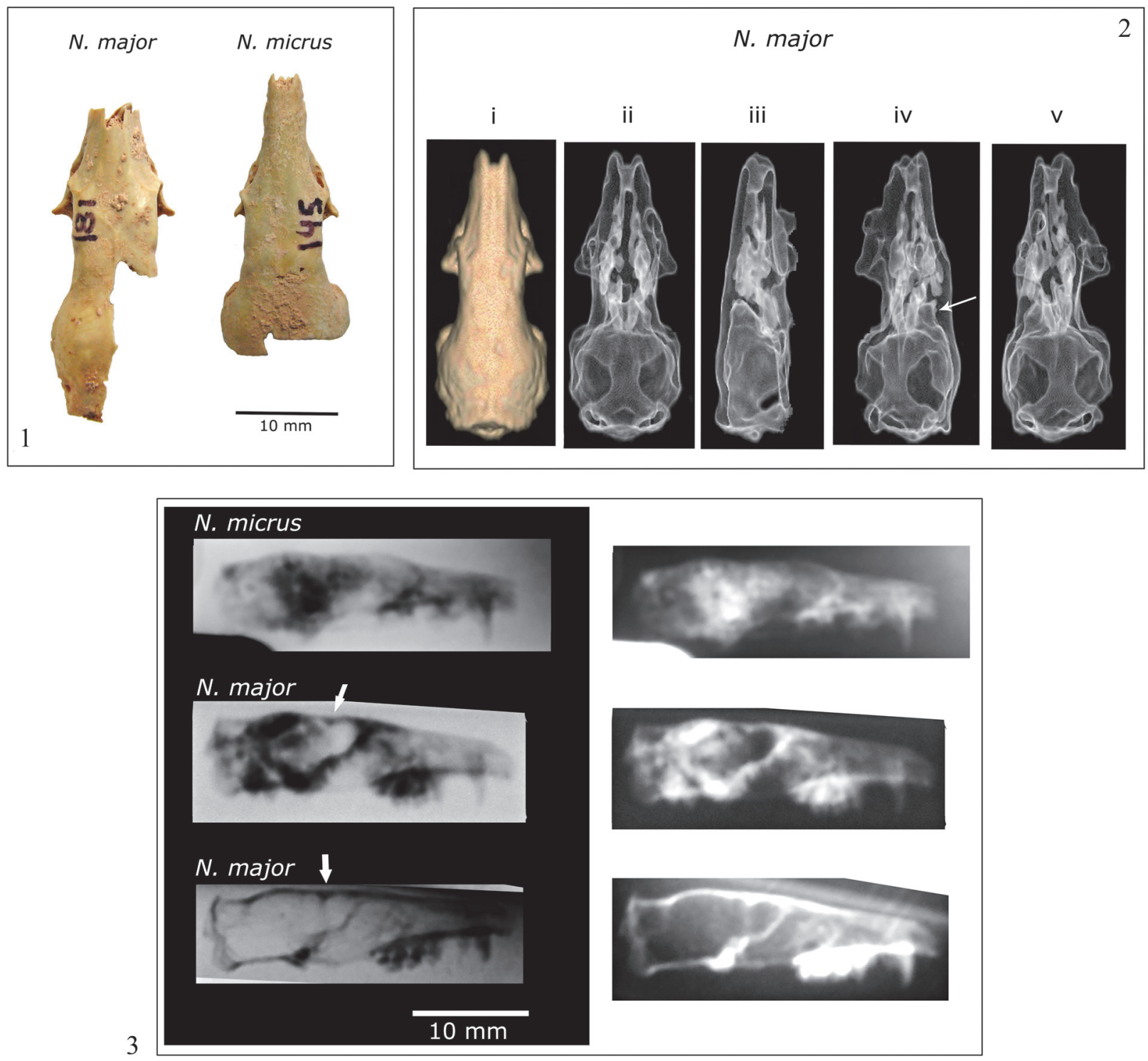

FIGURE 1. Natural (1), digital (2), and radiographic images (3) of Nesophontes spp. crania used in this study. 1, these skulls were the source of natural endocasts for Nesophontes micrus (C145) and Nesophontes major (C181) shown in Figures 1 and 2. 2, Digital rendering of $N$. major skull (C133) from which the digital endocast in Figure 5 was reconstructed. 3, are negative and positive lateral radiographs of Nesophontes spp. endocranial morphology and space.

were compared to brain images in scientific literature, plus the Comparative Brain Collection at www.brainmuseum.org and Digital Morphology Library (Digimoph: www.digimorph.org/) of the University of Texas at Austin. Detailed comparisons were made with several multituberculates, basal eutherians, and extinct insectivorans as a source or morphological comparison, and not for phylogenetic purposes. These included the species Eoryctes melanus, Vincelestes neuquenianus, Hyopsodus lepidus, the extant marsupials Monodelphis domestica and Marmosa murina, plus the extant lipotyphlans Solenodon paradoxus, Tenrec ecuadatus, Erinaceus europeaus, and Sorex sp. Cranial and natural endocranial casts linear measurements were taken with digital calipers. Brain percentage compositions and angle measurements procedures were adopted from Stephan and Andy (1982) and Macrini et al. (2006). Marsupials were included not as an ancient or "primitive" outgroup, but because of their endocranial similarities, and their value in the study of placental neuroanatomy (Ashwell, 2010). Because of known problems with insectivoran nomenclature and phylogeny 
1
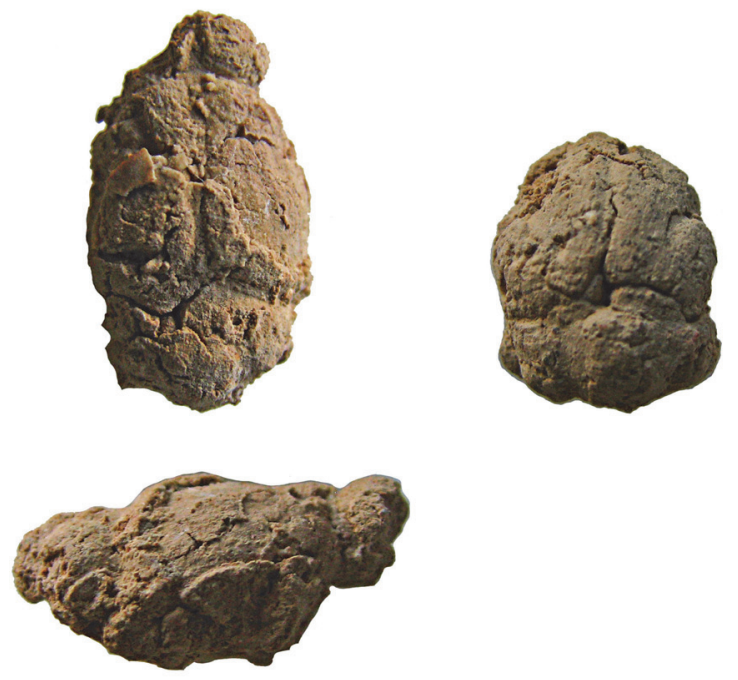

$10 \mathrm{~mm}$
2
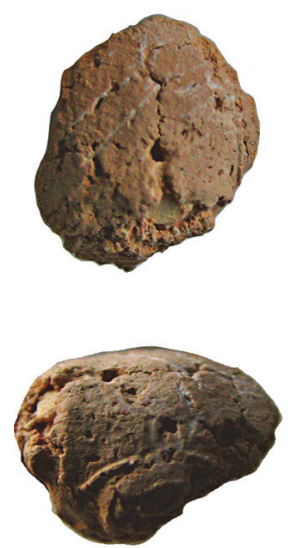

4

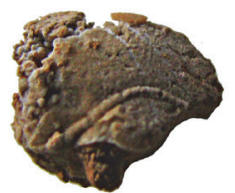

FIGURE 2. Natural endocranial casts of Cuban Nesophontes spp. 1, superior, and right lateral view of Nesophontes major (specimen number C181) endocasts. 2-3, superior and right lateral views of Nesophontes micrus endocasts. 2 , Nesophontes micrus (C145); 3-4, are not cataloged.

(Asher and Helgen, 2010) some of the older classification systems (e.g., classification of "progressive insectivorans" using EQ values) have been included in the text to serve as comparisons with older literature and will be referred to as actual genera or species when appropriate.

Digital endocasts were reconstructed from $\mathrm{x}$ ray computed tomography data (CT slices) acquired through the scanning of two nearly complete cranial specimens of Nesophontes micrus (C436, C437) and two of Nesophontes major (C133,C270). The specimens were scanned coronally with a General Electric Lightspeed scanner (VCT, 64 detectors), resulting in 120 images with a matrix size of $512^{2}$. The techniques used were a 20 milliampere current $(\mathrm{mA}), 80$ peak kilovolts $(\mathrm{KvP})$, a slice thickness of $0.625 \mathrm{~mm}$, plus a $0.312 \mathrm{~mm}$ image overlap in a $32 \mathrm{~mm}$ field of view. The scan data were then reconstructed with a General Electric ADW (4.3) Workstation using an "air-structure" algorithm.

Encephalization quotients (EQ) were calculated using Jerison (1973) equation: $E Q=E V / 0.12$ (Wt) ${ }^{0.67}$ and Eisenberg's (1981) equation: $E Q=E V /$ $0.055(\mathrm{Wt}){ }^{0.74}$, where $\mathrm{EV}=$ endocranial volume in $\mathrm{ml}\left(\mathrm{cm}^{3}\right)$ and $\mathrm{Wt}$ the body mass in grams $(\mathrm{g})$. Cal- culated EQ values were based on a body mass range between 97 and $114 \mathrm{~g}$ (average 105.5), estimated from the formula: $y=3.68 x-3.83$, where $y=$ $\log 10$ (body mass in grams), and $x=\log 10$ (skull length in $\mathrm{mm}$ ). This formula is based on the relationship between body mass and skull length documented in extant insectivore-grade mammals (Luo et al., 2001; Rowe et al., 2011). Skull lengths for Nesophontes micrus and N. major, plus other linear and volumetric features were measured (Table 1). Endocranial volumes and dimensions were measured directly from CT data with built-in measuring tools of the ADW software (Table 1). McFarlane (1999) provided a mass estimate for Nesophontes between 180 and $200 \mathrm{~g}$. However, this estimate is based on correlations between the significantly larger Nesophontes edithae from Puerto Rico and chipmunk-sized rodents (e.g., Allen, 1942, Walker et al., 1975) and could be an overestimation.

The terminology for brain anatomy follows Butler and Hodos (2005), Rowe et al. (2011) and Orliac et al., (2012), and that for cranial osteological follows McDowell (1958), Wible (2008), and Macrini (2012). The use of Lipotyphla over Eulipotyphla follows the suggestions of Asher and Helgen 


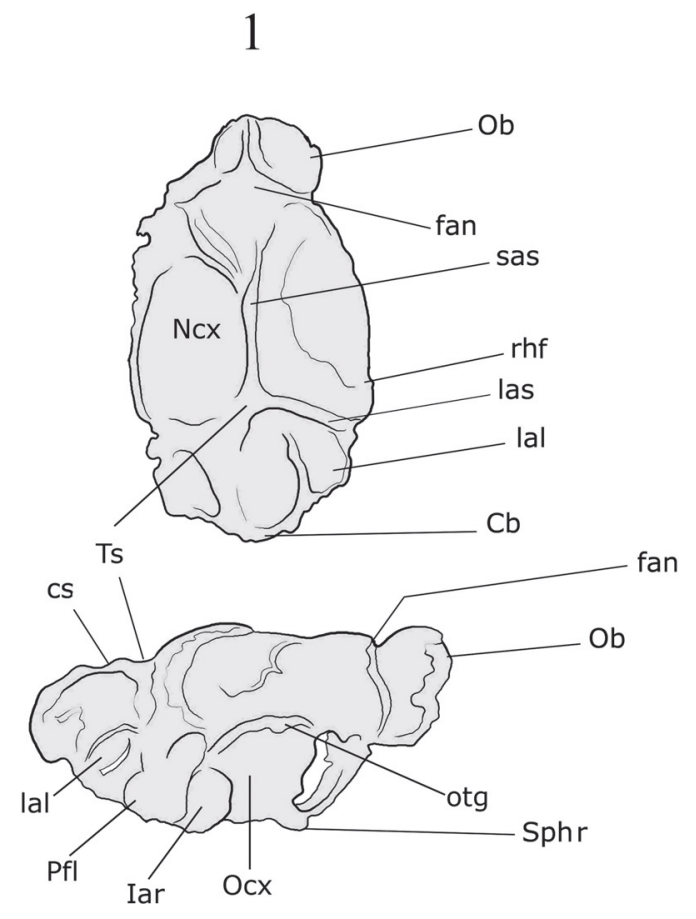

$10 \mathrm{~mm}$
2
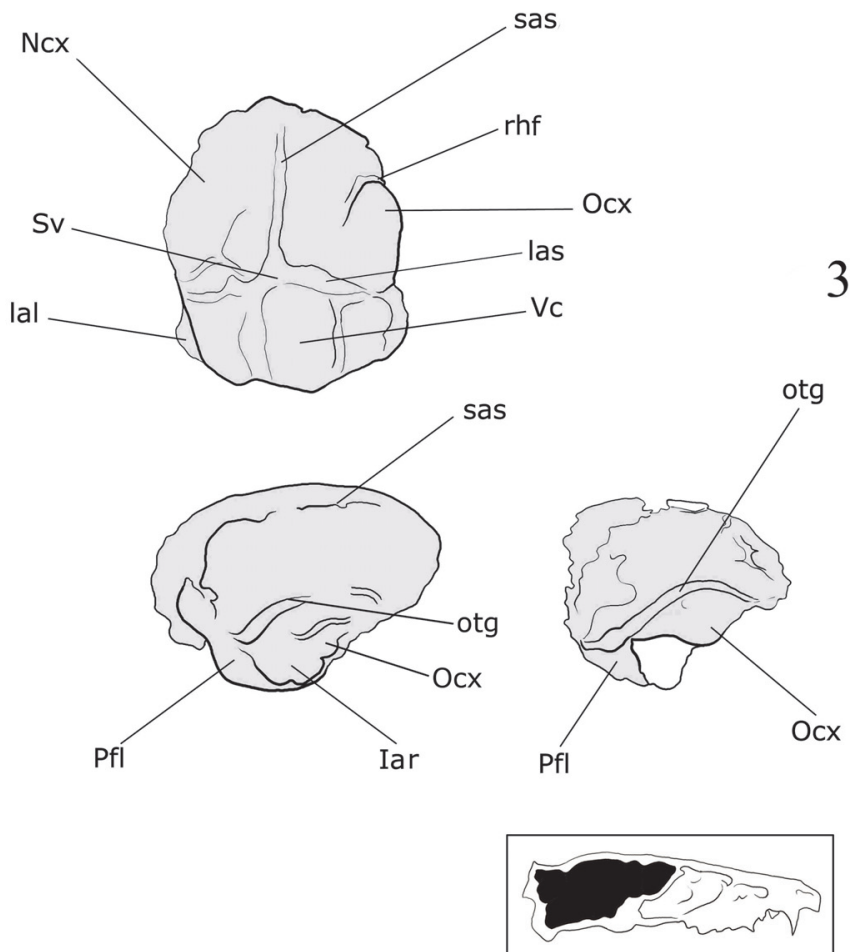

FIGURE 3. Anatomical terminology of Nesophontes endocranial casts. 1, superior and lateral views of Nesophontes major endocranial cast (C181). 2, superior and lateral views of Nesophontes micrus (C145) specimen. 3, single view of partial endocranial cast extracted from an uncataloged $N$. micrus skull. Abbreviations of anatomical terminology: Cb cerebellum; cs superior colliculi; fan annular or circular fissure; lar internal auditory region; lal lateral lobe of cerebellum; las lateral transverse sinus; Ncx neocortex; Ob olfactory lobes; otg orbitotemporal groove; Ocx olfactory (=piriform) cortex; Pfl paraflocculus; rhf rhinal fissure; sas sagittal sinus or longitudinal sinus; Sphr sphenorbital region; Sv confluence of the transverse and sagittal sinuses; Vc cerebellar vermis. $\mathbf{A}$ and $\mathbf{P}$ stand for anterior and posterior.

(2010). A list of character states for Nesophontes is provided in the Appendix.

\section{RESULTS}

\section{Forebrain: The Olfactory Lobes and Ethmoid- cribriform Region}

The casts of the olfactory lobes $(\mathrm{Ob})$ are large, well-developed, elongated anteroposteriorly, non-continuous, and oval in shape (Figures 2.1 and 4.2). The olfactory lobe casts are less than one half the anteroposterior length of the neocortex, but constitute $20-25 \%$ of the total endocranial volume. The sagittal or longitudinal sinus (sas) divides both lobe casts medially.

The olfactory lobe casts are divided anteriorly and anterodorsally by the crista galli and postero- dorsally by an annular or circular fissure (fan) on the posterior frontal bone (Figures 1.2-3, 2.1 and 4.2). Small sections of the olfactory peduncle casts were observed in well-preserved natural casts (Figure 4.2) and implied in digital endocasts (Figures $5.1,6.1$ ). Casts of olfactory nerve fibers were not observed in either natural or digital endocast. The olfactory lobes rest on a thick and inclined cribriform plate, rich in nasoturbinal and ethmoturbinal foramina (Figures 1.2-3, 6 and 8). Possible casts of olfactory extensions [onf] are visible superiorly and anteriorly on the olfactory lobes of digital renderings (Figure 5 and Figure 6). The dorsalmost might be a negative cast of the cribroethmoidal foramen (cef), which seems to be largest of the cribriform foramina in Nesophontes (Figure 8). The annular or circular fissure (fan), which separates the olfac- 

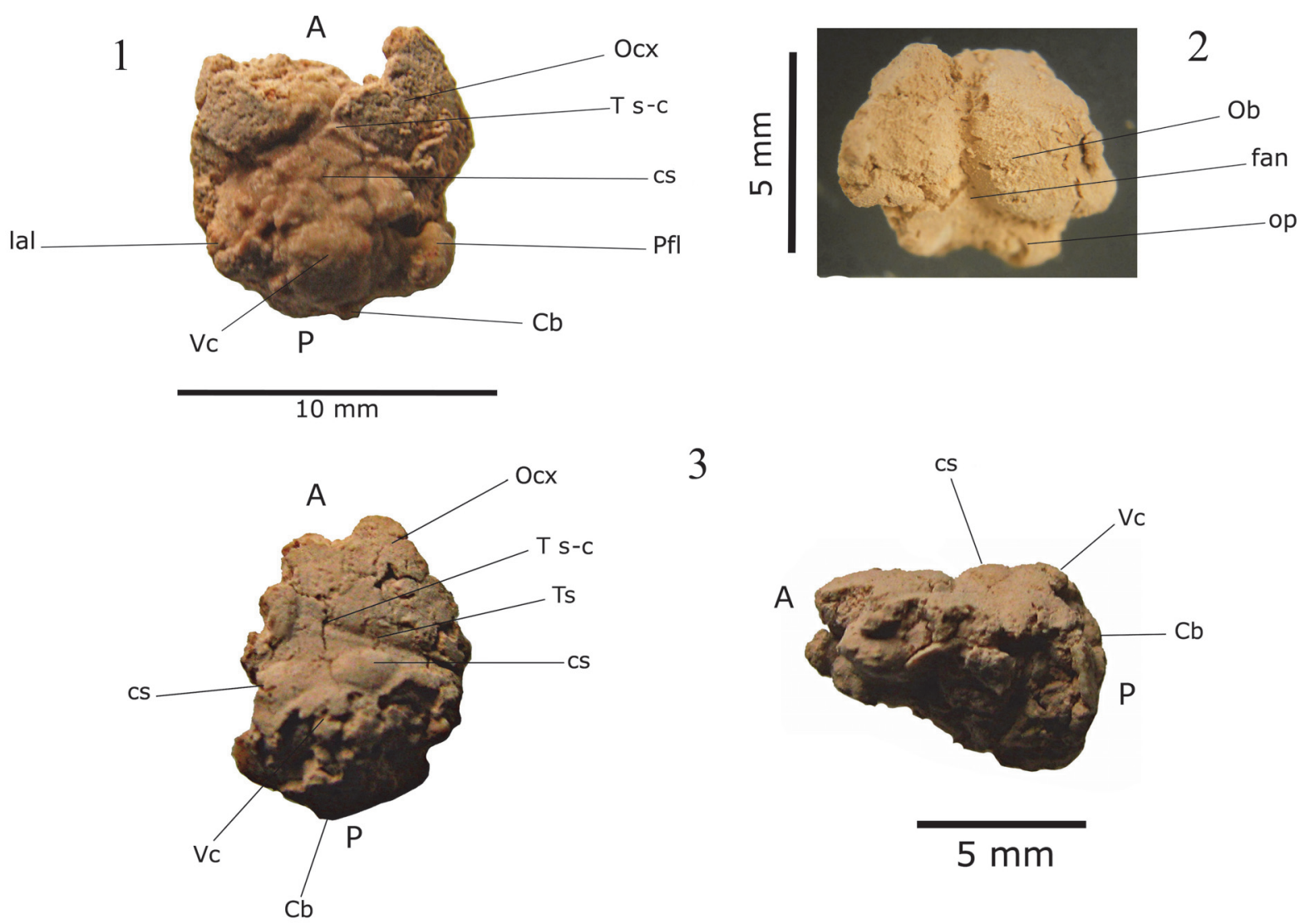

3

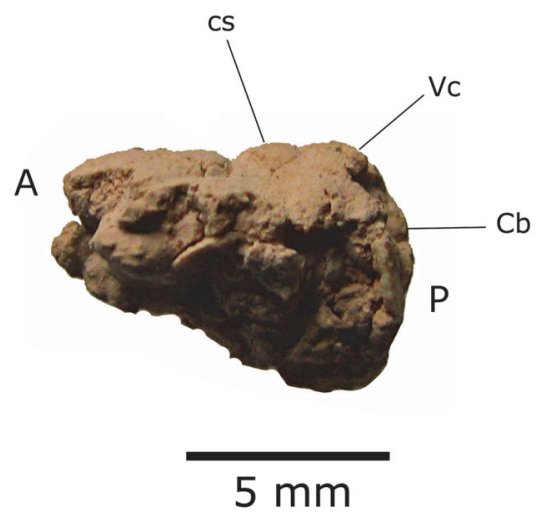

FIGURE 4. Natural endocranial casts extracted from Nesophontes spp. skulls. (4.1) Nesophontes major hindbrain fragment; (4.2) N. major olfactory lobes; (4.3-4.4) Nesophontes micrus superior (4.3) and left lateral (4.5) views of a partial hindbrain. Cb cerebellum; cs superior colliculi; lal lateral lobe of cerebellum; Ob olfactory lobes; op olfactory peduncle; Pfl paraflocculus; Ts transverse sinus canal; Ts-c confluence of the transverse and sagittal sinuses. A and $\mathbf{P}$ stand for anterior and posterior.

tory lobes from the neocortex, is apparently deep as it can be seen in radiographs, and digital and natural endocranial casts. The olfactory lobes are aligned to the rest of the brain, but with an endocranial flexure between 25 and 29 degrees. No evidence of accessory olfactory lobes were observed in Nesophontes casts.

\section{Forebrain: Cerebrum}

The cast of the neocortex (Ncx) is lissencephalic or smooth (poor gyrification). Only slight indications of sulci are visible on natural and digital cast specimens. These are superficial, and probable indications of the rhinal fissure (rhn) above the olfactory (= piriform) cortex (Ocx), and superiorly, behind the circular fissure (fan). The latter seems to be the sylvian fissure (Sf) (Figures 1.2, 5, and 6).

The cast of the neocortex is ovoid and divided by a shallow superior sagittal sinus. The casts of the hemispheres are elongated anteroposteriorly, narrower anteriorly, and wider posteriorly, at the level of the olfactory cortex (Ocx). The cerebral hemispheres are well defined.

A marked orbitotemporal groove (otg) cast is visible on most natural endocasts (Figure 2), but not on digital renderings (Figures 5 and 6). Such a structure is often defined as a sinus canal or meningeal vessel, and is visible on the endocranial face of the squamosal bone (Thewissen and Gingerich, 1989; Silcox et al., 2011). This feature is a probable marker of the rhinal fissure, delimiting between the paleo and neocortex (Rowe, 1996; Silcox et al., 2011). The transverse sinus seems deeper and wider than the sagittal sinus. Traces of the sagittal and transverse sinuses meet just before the tectum (Figures 2 and 4).

\section{Diencephalon}

The digital renderings show a hypophyseal fossa (hyf) and sphenoid tracts with optic nerves in the anterior-inferior region that can represent the optic chiasm (Och). The sphenoid tracts seem to 


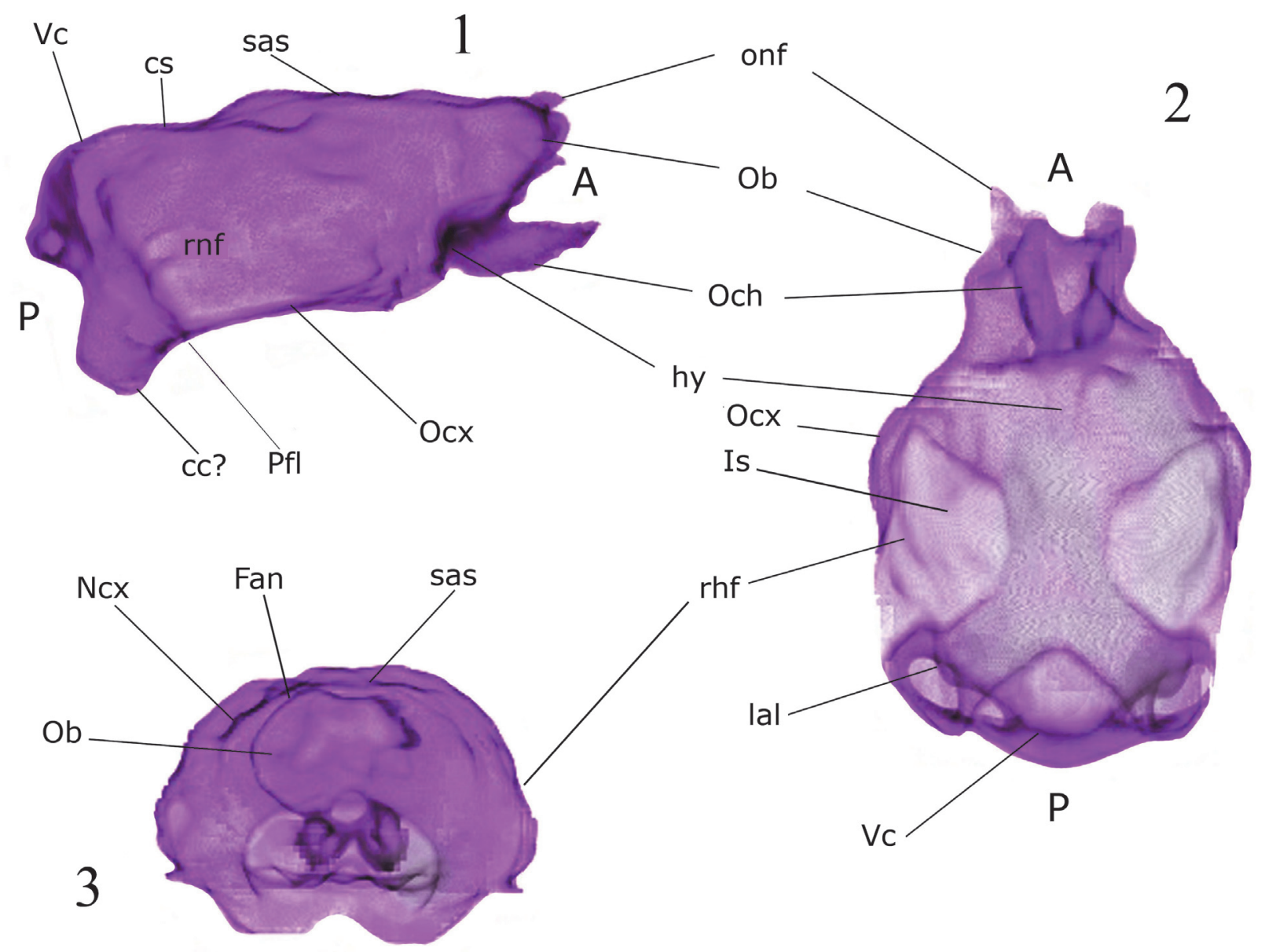

FIGURE 5. Digital endocranial cast of Nesophontes major (C133) in right lateral (1), anterior (2), and inferior (3) views. Abbreviations: $\mathbf{C b}$ cerebellum; cc possible cast of spinal cord space; cs superior colliculi; fan annular or circular fissure; hy hypophyseal fossa; lar internal auditory region; lal lateral lobe of cerebellum; las lateral transverse sinus; Ncx neocortex; Ob olfactory lobes; Och. optic chiasm; Ocx olfactory (=piriform) cortex, onf olfactory nerve fiber, otg orbitotemporal groove; Pfl paraflocculus; rhf rhinal fissure; sas sagittal sinus or longitudinal sinus; Sphr sphenorbital region; Sv confluence of the transverse and sagittal sinuses; Vc cerebellar vermis. $\mathbf{A}$ and $\mathbf{P}$ stand for anterior and posterior.

be divided anteriorly by the alisphenoid, and are separate from the optic foramina (Figure 5). The olfactory cortex cast and the sphenorbital region are visible, but were not well delimited on natural or digital endocasts (Figure 9 and 10).

\section{Midbrain: Tectum}

The midbrain shows marked superior colliculi casts posterior to the confluence of the transverse sinus (Figures 2.1-2, 4.1, and 4.3). The midbrain seems to have been exposed with very little or no space between cerebrum and cerebellum. The tectum seems to be continuous superiorly and through between the cerebrum and cerebellum, unlike Solenodon or Tenrec, in which the tectum is exposed, but separated from both cerebrum and cerebellum (Figure 9, 10, 11, 12; see Discussion).
Casts of colliculi appear posterior to the confluence of the transverse and sagittal sinuses at the same level. Colliculi are not visible on all natural specimens, and are also not visible on the digital endocasts. The variation in presence or absence of colliculi casts seems to be an artifact of preservation, and indicates the low resolution of both the natural and digital endocasts in which they are not evident. However, they are suggested by the presence of impressions inside the osseous roof of the braincase (Figure 9). However, on the digital renderings, there is indication of only one set of colliculi, which most probably represents superior colliculi. Presumably, inferior colliculi were present in the living animal, as in all extant mammals, but not visible on the endocasts (Macrini 

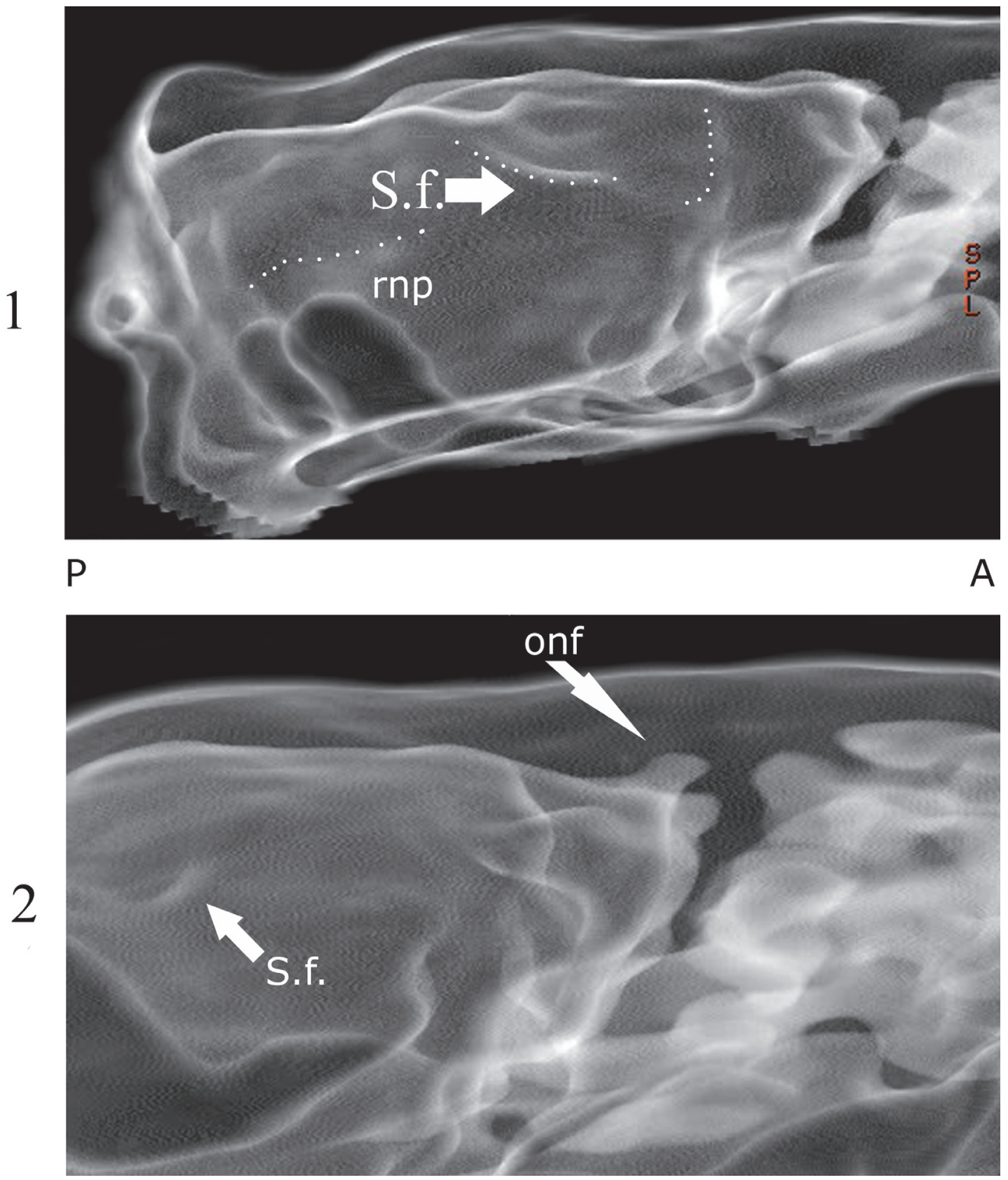

FIGURE 6. Volume rendering of Nesophontes major (C133) endocranial space in lateral (1) and oblique (2) views showing possible olfactory nerve fibers (onf), sylvian fissure (S. f.), and rhinal fissure (rhf). A and $\mathbf{P}$ stand for anterior and posterior.

pers. comm., 2012). There was no osseous tentorium in any of the specimens studied.

\section{Hindbrain: Cerebellum}

The cast of the cerebellum is large and as wide as the neocortex. The vermis's cast is thick, wide, and lies slightly higher than the rest of the cerebellum (Figures 2 and 4). Folia or fissures are not visible on either natural or digital casts of the cerebellum. There are two prominent casts of lat- eral lobes (=cerebellar hemispheres), and paraflocculi. The casts of the paraflocculi are ovoid, much smaller than the cerebellar lobe and project laterally (Figures 2 and 4 ).

Endocasts extracted from Nesophontes micrus and Nesophontes major crania seem to be slightly different morphologically. The endocranial casts of $N$. major (C181) show a narrower cerebrum and cerebellum than those of $N$. micrus (C145). The tectum is wider and more conspicuous 


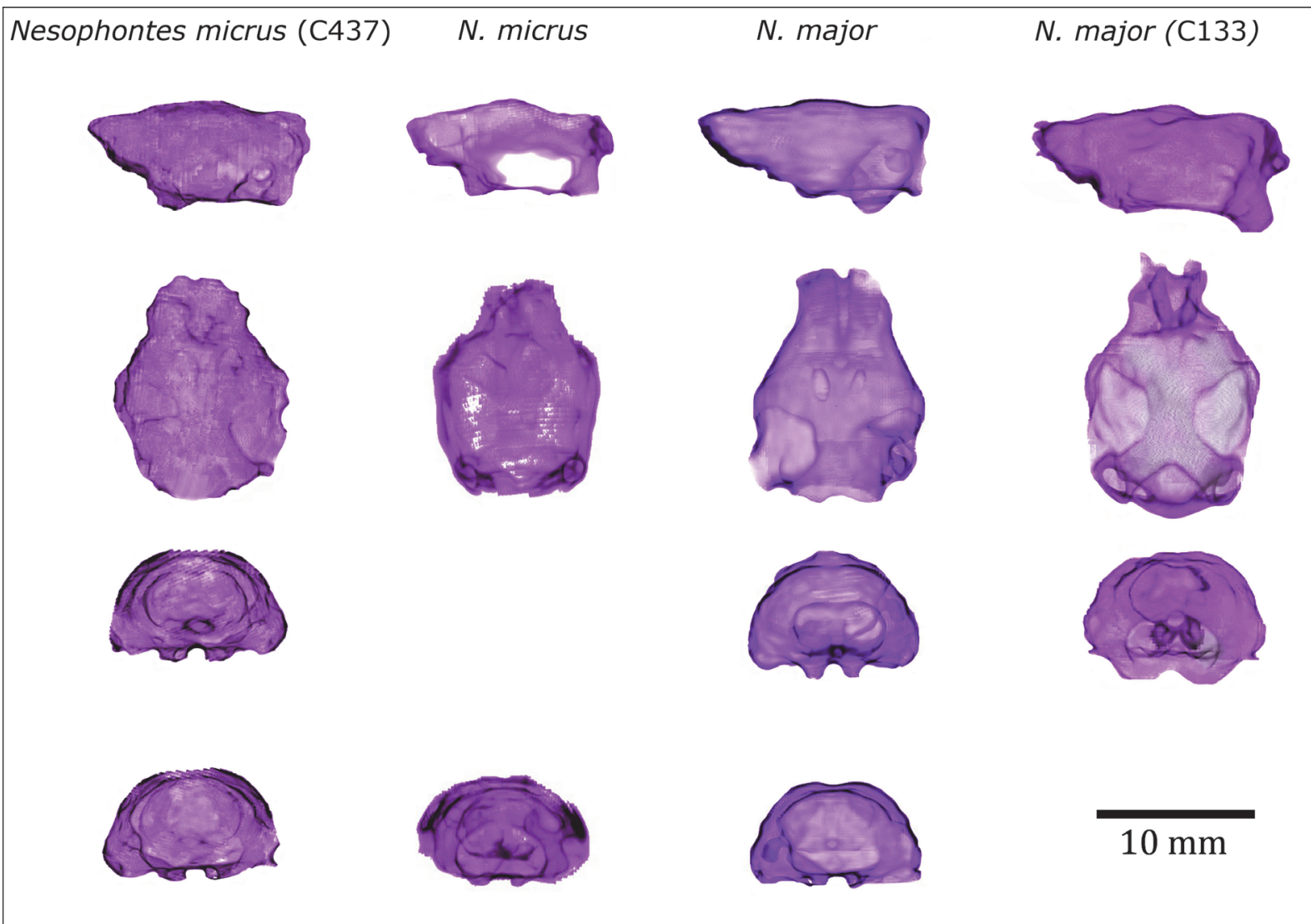

FIGURE 7. Endocranial casts of Cuban Nesophontes spp. Nesophontes micrus (C437) first column. Endocast volume: $0.580 \mathrm{~mL}$, encephalization quotients (EQ 2 and 3): 0.21 and 0.33. Nesophontes micrus (C436), second column. Endocast volume: $1.231 \mathrm{~mL}, \mathrm{EQ} 2$ and 3: 0.33 and 0.52. Nesophontes major (270), third column. Endocast volume: $0.729 \mathrm{~mL}$, EQs: 0.27 and 0.43 . Nesophontes major (C133), fourth and last column. Endocast volume: $0.888 \mathrm{~mL}$, EQs: 0.36 and 0.57 .

in N. micrus than in N. major (Figure 9). The cerebrum and the vermis are wider and rounder in $N$. micrus (C145). The colliculi impressions on the braincase are deeper and slightly more separated in N. major than in N. micrus. The confluence of the transverse sinus appears to be deeper and wider in $N$. major. Differences are visible in the x-ray images and inner molds of their braincase (Figures 1.3 and 9$)$.

\section{Measurements and EQ Values}

The volume of all endocasts was estimated between 0.76 and $1.23 \mathrm{ml}$, which suggest a brain mass of nearly, or slightly heavier than $1 \mathrm{~g}(\approx 1 \mathrm{~g} /$ $\mathrm{cm}^{3}$ ). Encephalization quotients calculated from Eisenberg's (1981) equation $\left(E Q^{3}\right)$ ranged between 0.33 and $0.57(n=4$; mean $=0.46)$ for both species. The EQ estimates calculated with Jerison's (1973) formula $\left(E^{2}\right)$ are slightly smaller with values between 0.21 and $0.36(n=4$; mean=0.29) (Table 1) and Figure 12 (Appendix). Of these, and despite the overlap, Nesophontes major seem to have larger EQ scores, probably due to their larger brain mass and volume.

\section{Discussion}

This study supports that the endocranial morphology of Nesophontes resembles that of placental, insectivore-grade mammals, especially the lipotyphlans. Within this clade, it is most morphologically similar to Solenodon despite their different molar morphology (Figure 12). Unfortunately, because endocranial casts of juvenile specimens were not available, developmental variation was not studied.

The olfactory lobes seem continuous in the digital endocasts, but are markedly separated by the circular fissure in natural endocasts and lateral radiographs (Figures 1.1, 1.3, and 4.2). Casts of olfactory nerve fibers are visible only on digital casts and could be negative renderings of the cribroethmoidal foramen (cef) (Figure 6). Such an 
TABLE 1. Linear and volumetric mean values of Nesophontes natural and digital endocasts.

1 Total cranium length range (minimum and maximum) taken from $N$. major $(\mathrm{n}=24)$ and $N$. micrus $(\mathrm{n}=12)$ from the same assemblage. * Estimated body mass calculated from the relationship $y=3.68 \mathrm{x}-3.83$, where $y=\log 10$ (body mass in grams), and $x=\log 10$ (skull length in $\mathrm{mm}$ ) following Luo et al. (2001) and Rowe et al. (2011); EQ ${ }^{2}$ formula from Jerison (1973), and $E Q^{3}$ formula from Eisenberg (1981). Greater than (>) and less than (<) signs used are to indicate measurements on incomplete specimens. The number given after the sign is the minimum measurement that was taken on the specimen. The labels $L$ (=left) and $R$ (=right) are applied to the measurements of bilateral structures such as the olfactory lobes.

\begin{tabular}{|c|c|c|c|c|}
\hline \multirow[t]{2}{*}{ Measurement } & $\begin{array}{l}\text { N. micrus } \\
\text { (C145) }\end{array}$ & $\begin{array}{c}\text { N. major } \\
\text { (C181) }\end{array}$ & $\begin{array}{l}\text { N. major } \\
\text { (C133) }\end{array}$ & $\begin{array}{l}\text { N. micrus } \\
\text { (C436) }\end{array}$ \\
\hline & \multicolumn{2}{|c|}{ Natural Endocasts } & \multicolumn{2}{|c|}{ Digital Endocasts } \\
\hline Cranium length $(\mathrm{mm})$ from specimen & $>27.5$ & $>31.0$ & 32.1 & 28 \\
\hline Cranium length min. $(\mathrm{mm})^{1}$ & 26.9 & 30.3 & 30.3 & 26.9 \\
\hline Cranium length max. $(\mathrm{mm})^{1}$ & 29.1 & 32.5 & 32.5 & 29.1 \\
\hline Estimated body mass $(\mathrm{g})^{*}$ & 97.37 & 110.2 & 114.3 & 99.21 \\
\hline Estimated body length (mm) & $\approx 110-135$ & $\approx 120-140$ & $\approx 120-140$ & $\approx 110-135$ \\
\hline$y=$ Log 10 value $^{*}$ (Body mass units) & 1.99 & 2.04 & 2.05 & 2 \\
\hline$x=\log 10$ value $^{*}$ (Cranial length) & 1.44 & 1.49 & 1.51 & 1.45 \\
\hline Estimated endocast volume (ml) & $>0.76$ & 1.09 & 0.888 & 1.231 \\
\hline Calculated endocast volume (ml) (from formula) & 0.844 & 0.997 & 1.043 & 0.856 \\
\hline Endocast total length (mm) & $>14.48$ & $>15.18$ & 15.2 & 14 \\
\hline Endocast total width (mm) & 9.86 & 9.65 & 9.4 & 9.7 \\
\hline Olfactory bulb length (mm) & $3.65-3.69$ & R 3.60 & L 3.0 - R 3.1 & incomplete \\
\hline Olfactory bulb width (mm) & 7 (both) & R 3.86 & 6.4 (both) & incomplete \\
\hline Cerebellum length (mm) & 5.97 & $4.58-5.22$ & 6.2 & 5.9 \\
\hline Cerebellum width (mm) & $7.45-8.4$ & 7.32 & 7.7 & 7.4 \\
\hline Brain-Cranium length ratio & 52.6 & 49 & 47.3 & 50 \\
\hline Encephalization Quotient $(E Q)^{2}$ & 0.33 & 0.35 & 0.36 & 0.33 \\
\hline Encephalization Quotient $(E Q)^{3}$ & 0.52 & 0.56 & 0.57 & 0.52 \\
\hline
\end{tabular}

intricate system of cribriform foramina is reminiscent of Solenodon as illustrated in Wible (2008, figure 23).

The neocortex of Nesophontes is ovoid and nearly lissencephalic in both the natural and digital endocasts. There are faint indications of sylvian and rhinal fissures (Figures 2.2, 5, and 6). Gyrencephalic brains of mammals, such as apes, are known to produce lissencephalic endocasts due to the covering of thick meninges (Clark, 1959; Macrini et al., 2007a). Presently, gyrification is correlated with brain mass and size (Pillay and Manger, 2007). The low gyrification seen in endocranial casts of Nesophontes is plausibly an artifact of its small brain size and mass (Martin, 1981; Pillay and Manger, 2007).

The traces of the rhinal fissure in Nesophontes separates the neocortex from the olfactory cortex very low and laterally as in Solenodon, but not as superiorly as in Erinaceus or Tenrec (Figure 12) (Leche, 1907; Allen, 1910; Stephan and Andy, 1982). The orbitotemporal groove seen on natural and digital endocasts (Figures 2, 3, and 5) marks the location of the rhinal fissure and suggests that the olfactory cortex was lower in the neocortex than the extant lipotyphlan Sorex, Blarina, and Scalopus. Overall, it resembles the extent observed in Solenodon and Condylura (Stephan and Andy, 1982).

Exposed colliculi are reported for most tenrecids and ericnaceids (Clark, 1932; Stephan et al., 1991; Orliac et al., 2012). In the afroinsectivoran Tenrec, and the lipotyphlans Ericaceus, Sorex, and Condylura, the tectum is not superiorly continuous with the cerebellum. Instead, it arises, exposed, from under the neocortex (telencephalon) to join the cerebellum. There is a small gap between the telencephalon and the cerebellum in three men- 


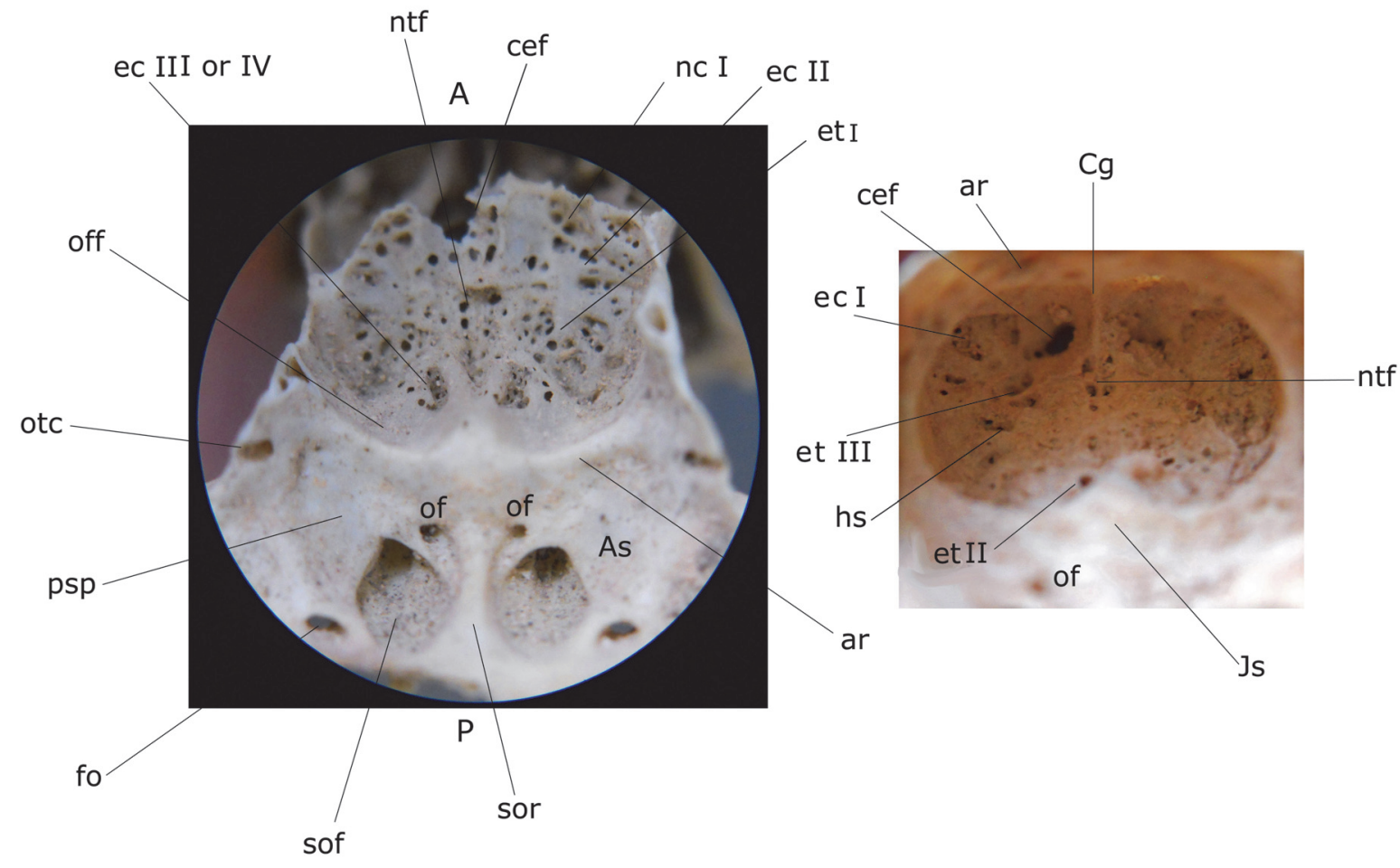

FIGURE 8. Cribriform and olfactory regions in Nesophontes major (1) and Nesophontes micrus (2). Abbreviations: ar annular ridge; As alisphenoid; cef cribroethmoidal foramen; cg crista galli; ec ectoturbinal foramina; etl ethmoturbinal foramina; fo foramen ovalae; hs horizontal sulcus; Js jugun sphenoidalis; nc nasocribriform foramina; ntf nasoturbinal foramina; of optic foramen for optic nerve; off olfactory fossa; otc orbitotemporal canal; psp parasphenoid plate; sof sphenorbital fossa; sor sphenorbital ridge. A and $\mathbf{P}$ stand for anterior and posterior.

tioned species, where the tectum is nearly totally exposed, and thus visible (Stephan and Andy, 1982; Macrini et al., 2007 b; Figures 9 and 10). Conversely, the tectum in Nesophontes is not as exposed as in Solenodon, Erinaceus, or Tenrec (Figures 10, 11, and 12). Natural endocasts suggest a slight and shallow gap between Nesophontes's telencephalon and cerebellum (Figures 2 and 4.3), in which the tectum is not completely exposed. In the endocranial casts of Nesophontes only one set of colliculi casts are visible (Figures 10 and 11). These were presumably present, but hidden under the telencephalon or cerebellum, or poorly preserved in the endocranial casts studied. The state of Nesophontes resembles that of Solenodon paradoxus as shown in Allen (1910) and Stephen and Andy (1982) in which the tectum is exposed superiorly, but one set of colliculi are covered by the neocortex.

The endocranial casts of Nesophontes resembles that of the extinct condylarth Hyopsodus and the palaeoryctid Eoryctes in being nearly superiorly continuous, and having partially or totally exposed colliculi (Figures 10 and 11). The gap between the tectum and cerebellum was not wide enough to expose all sets of colliculi in Nesophontes. This state, as observed in Nesophontes endocasts, is intermediate with that present in Tenrec (totally exposed) and Microgale or Sorex (totally hidden) (Figures 11 and 12). In Tenrec, there is a wide gap between the posterior part of the cerebral hemispheres and the cerebellum from which the midbrain appears, exposing the tectum (Figure 12). In Microgale, however, there is no gap between the neocortex and the cerebellum. This feature seems hidden in Sorex, Blarina, and Scalopus (Figure 12).

Tectum exposure of the midbrain is correlated with a slight neocortical extension, and secondary sensory specialization as documented in bats (Edinger, 1964; Orliac et al., 2012). Yet, this exposure usually leaves faint, if any, marks on the braincase (Orliac et al., 2012). However, there are slight 


\section{N. micrus}

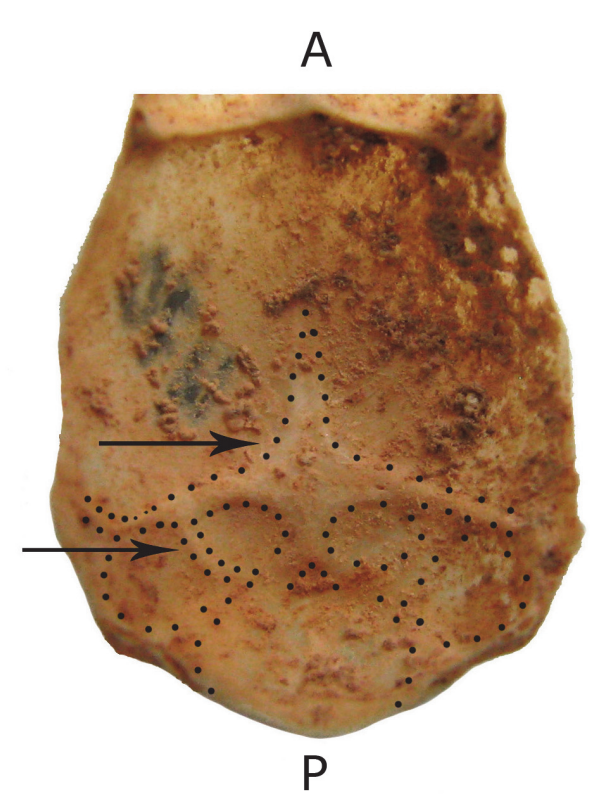

\section{N. major}

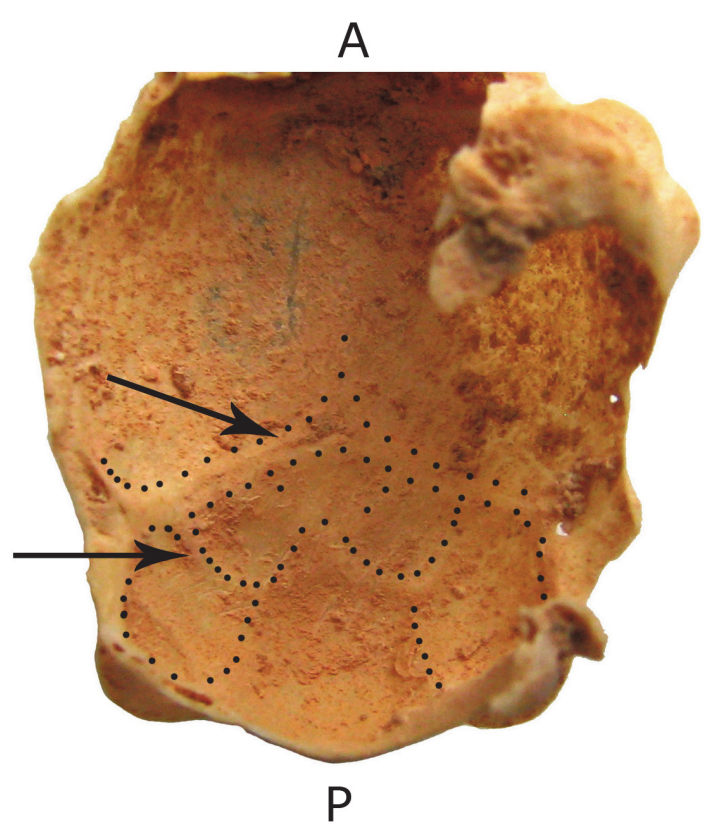

\section{$10 \mathrm{~mm}$}

FIGURE 9. Endocranial morphology of Nesophontes micrus and Nesophontes major calotte showing slight differences in tectum and transverse sinus. Top arrows point to the confluence of the transverse sinus and the colliculi fossae. $\mathbf{A}$ and $\mathbf{P}$ stand for anterior and posterior.

collicular imprints inside of the Nesophontes braincase (Figure 9). The slight differences noted between $N$. micrus and $N$. major endocranial casts lie especially in the neocortex and tectum. The neocortex of $N$. micrus is slightly wider, with more visible sylvian and rhinal fissures, plus orbitotemporal groove (otg). The confluence of the transverse sinus is less angled, deeper, and wider in $N$. micrus. The superior colliculi seem more pronounced in N. micrus (Figure 9). Unfortunately, there is not enough evidence now to support that these differences are of interspecific value considering the high level of intraespecific variation in Nesophontes (Figure 7) (Silva-Taboada et al., 2007 and literature cited therein).

Cerebellar hemispheres or lateral lobes, vermis and paraflocculus are all visible in the endocranial casts of Nesophontes as in other placentals (Macrini et al., 2007 b; Rowe et al., 2011). Widening of the cerebellar hemispheres, and distinction between its parts in Nesophontes's casts, resemble Solenodon and tenrecids in general. The casts of the vermis are not round and centrally located such as that of the stem therian Vincelestes, but are elevated and medially located like those of Solenodon, Erinaceus, and Sorex (Figure 12) (Stephan and Andy, 1982; Macrini et al., 2007 b). Unfortunately, casts of the paraflocculi were not all complete, but indications on natural and digital casts suggest that these were round structures, projecting postero-laterally and low in the cerebellum (Figures 2.1, 4.1, and 5.1). Future study on the ear structure of Nesophontes can shed light on the relationship between the paraflocculi and the semicircular canal within the inner ear.

Characters such as enlargement and widening of the cerebellum with marked cerebellar parts are considered derived conditions in ancestral therians (Kielan-Jaworowska et al., 2004; Rowe et al., 2011). The neocortex covering of the midbrain tectum is apparent in many different lineages of extant mammals; such dorsal exposure of the tectum is considered a likely condition of ancestral or early mammals (Kielan-Jaworowska et al., 2004; Macrini et al., $2007 \mathrm{~b}$ ). 


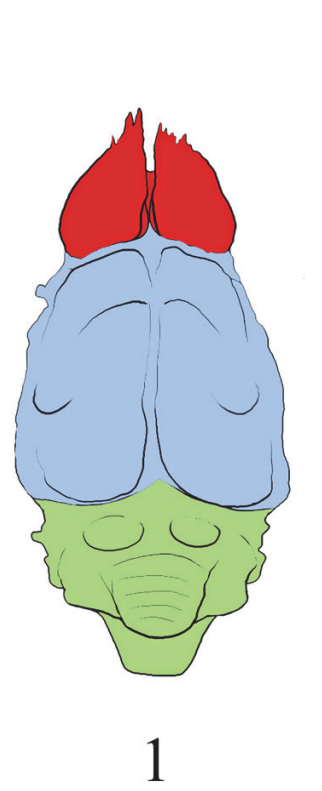

A

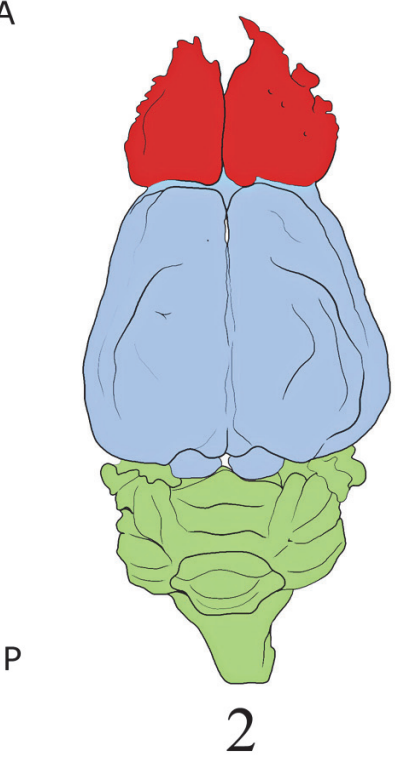

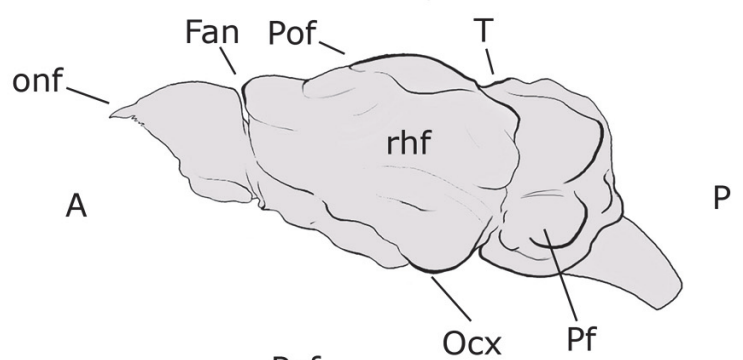

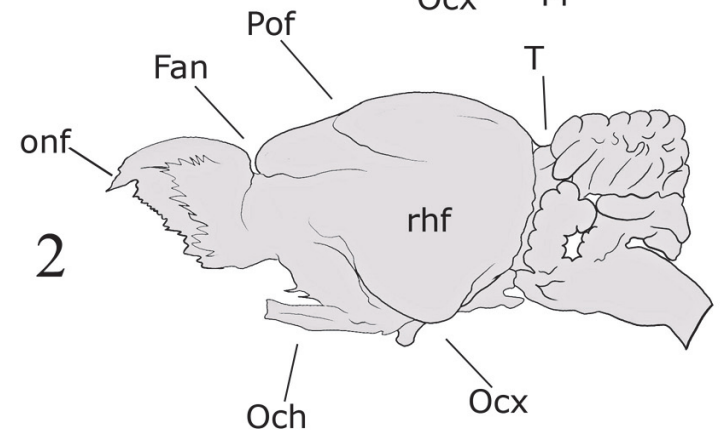

FIGURE 10. Idealized brain reconstruction of Nesophontes spp (1), and Solenodon paradoxus (2) in superior and lateral views. The brain of Nesophontes is a composite reconstruction based on natural and digital casts. Solenodon paradoxus was drawn from photographs of Stephen and Andy (1982:541, figures 20-22). Lines and labels on the lateral views indicate similar morphologic features. Olfactory lobes are in red, neocortex is in blue, and posterior brain (part of midbrain and cerebellum) is in green. Specimens are not to same scale. Abbreviations: $\mathbf{C b}$ cerebellum; cs superior colliculi; Fan annular or circular fissure; lar internal auditory region; lal lateral lobe of cerebellum; las lateral transverse sinus; Ncx neocortex; Ob olfactory lobes; Och optic chiasm; Ocx olfactory (=piriform) cortex; onf olfactory nerve fiber; otg orbitotemporal groove; Pfl paraflocculus; Pof post-orbital fissure; rhf rhinal fissure; sas sagittal sinus or longitudinal sinus; Sphr sphenorbital region; Sv confluence of the transverse and sagittal sinuses; $\mathbf{T}$ tectum; Vc cerebellar vermis. $\mathbf{A}$ and $\mathbf{P}$ stand for anterior and posterior.

For comparative purposes with older methodology and literature, encephalization quotients (EQ) of insectivoran-grade mammals are compared to that of Nesophontes. These "progressive insectivorans" are said to be progressive because of larger brains, and higher EQ estimates related to specialized behavior seen in fossorial and semiaquatic adaptations (Stephan and Andy, 1982). The EQ estimates for both N. micrus and N. major lie below those for the "evolved insectivorans" of Bauchot and Stephan (1967), and are intermediate to the "progressive insectivores" of Stephan and Andy (1982), and most of the crown mammals in Rowe et al. (2011). The "progressive insectivores" of Stephan and Andy (1982) included the following taxa: Desmana, Talpa, and the semiaquatic Potomogale, whereas Solenodon, Oryzorictes, and Microgale were considered "slightly progressive" or intermediate between groups. Nesophontes EQ values lie within the range of the extant Solenodon paradoxus, Erinaceus spp., plus the marsupials Monodelphis and Didelphis. Their range is also comparable to the extinct multituberculate Kryptobaatar, Chulsanbaatar, and the also extinct primitive eutherian Asioryctes, but is larger than the stem therian Vincelestes and the primitive eutherian Kennalestes (Kielan-Jaworowska et al., 2004; Rowe et al., 2011).

\section{Especial Comparison with Solenodon}

Except for their difference in size and dentition, the brain and facial anatomy of Nesophontes is similar to that of tenrecids, and even more so to Solenodon (Figure 11). This similarity extends to cranial rostral musculature and its osseous morphology (Anthony, 1918; McDowell, 1958; Asher, 2001). These similarities seem to suggest Nesophontes and Solenodon are ecomorphs. The faciomaxillary morphology of Nesophontes is similar to that of Solenodon in having similar muscular arrangements, cranial osteology, and grooved anterior dentition. In Nesophontes, the maxillary canines are grooved. In Solenodon, the second inferior incisor (i2) is grooved for venom delivery 


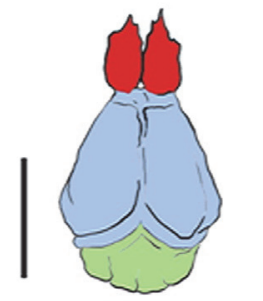

Monodelphis domestica

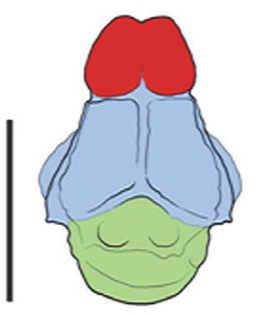

Eoryctes melanus

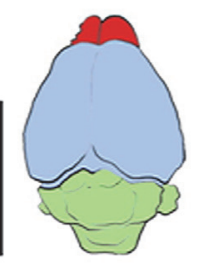

Marmosa murina

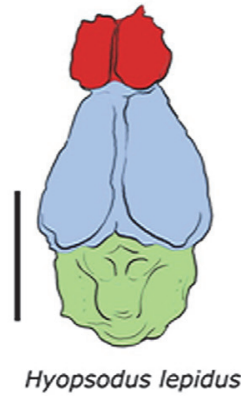

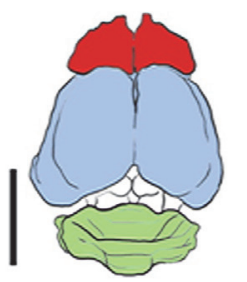

Erinaceus europeus

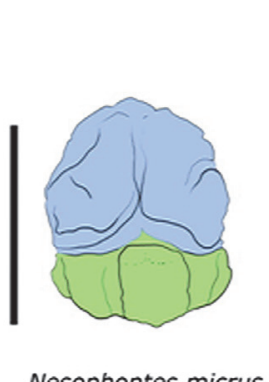

Nesophontes micrus

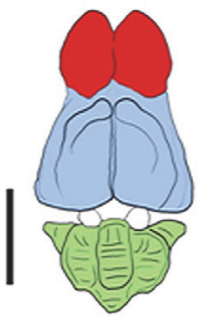

Solenodon paradoxus

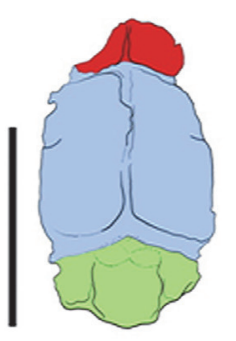

Nesophontes major

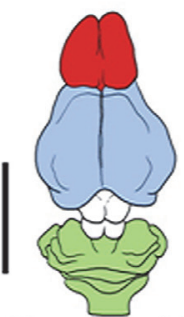

Tenrec ecuadatus

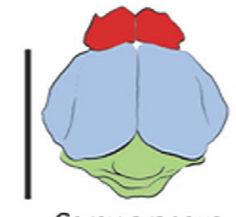

Sorex araneus

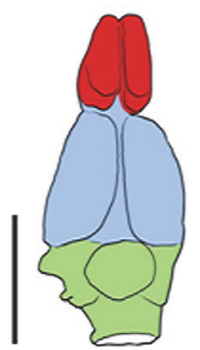

Vincelestes neuquenianus

FIGURE 11. Brain morphology of selected extinct and extant mammals, including Nesophontes spp. Upper row contains extant placentals and marsupials. Lower row contains extinct taxa and Nesophontes. Olfactory lobes are in red, neocortex is in blue, and hindbrain is in green. Scale bar equals $10 \mathrm{~mm}$. Sources: Monodelphis domestica drawn from Rowe et al. (2011); Solenodon paradoxus from Allen (1910); Tenrec ecuadatus from Stephan and Andy (1982); Eoryctes melanus from Thewissen and Gingerich (1989); Hyopsodus lepidus from Orliac et al. (2012); Vincelestes neuquenianus from Macrini et al. (2007a) Nesophontes taxa reported here, and the remaining from the Comparative Brain Collection at www.brainmuseum.org. A and $\mathbf{P}$ stand for anterior and posterior. Scale bar $=1 \mathrm{~cm}$.

(Gundlach, 1877; McDowell, 1958; Silva-Taboada et al., 2007; Ligabue-Braun et al., 2012). The similar characteristics include pronounced faciomaxillary musculature scars for the levator labii, levator labii, and erector vibrissarum on the superior-lateral aspects of the maxilla (Allen, 1910; MacDowell, 1958; Wible, 2008). Other characters, such as the absence of accessory bulbs on olfactory lobes and the presence of prootic canal seem to be unique states in Solenodon and Nesophontes in comparison to other lipotyphlans (Stephan and Andy, 1982; Wible, 2008). Casts of the olfactory lobes in Nesophontes do not show presence of accessory olfactory lobes, as also not reported for Solenodon (Stephan and Andy, 1982: 540). In addition, Nesophontes has a double prootic canal (canalis prooticus), whereas Solenodon has a single canal (Wible, 2008). Prootic canals are not reported from other placental mammals, but have been widely reported in Cenozoic mammaliaforms (Wible, 2008).

\section{Behavioral and Ecologic Inferences}

By considering the marked similarities of the nesophontid endocranium with those of Solenodon and the Tenrec it is possible to deduce its sensitiv- ity to auditory and olfactory stimuli. Barton and colleagues (1995) showed that nocturnal species tended to have larger olfactory structures than diurnal species; fossorial species had smaller optic nerves than those of non-fossorial adaptations. They did not find optic nerve size exclusive of either nocturnal or diurnal adaptation. The marked development of the olfactory lobes and superior colliculi in Nesophontes suggests that it lived in habitats where olfaction and acoustic capabilities were crucial (Scalia and Winons, 1975; Catania, 2005). Nesophontes was probably nocturnal, as indicated by its abundance in owl pellet remains (Silva-Taboada et al., 2007) and fossorial as suggested by its minute optic nerve foramen (0.27$0.58 \mathrm{~mm}, \mathrm{n}=8$ ) (Barton et al., 1995), plus welldeveloped auditory and tactile systems as in other mammals adapted to nocturnal environments (Jerison, 1973; Scalia and Winons, 1975; Kielan-Jaworowska et al., 2004; Catania, 2005). The presence of superior colliculi suggests that the vision of Nesophontes was probably not as poor as in other lipotyphlans (e.g., Sorex) (May, 2005). Instead, it implies that Nesophontes depended on inputs from the retina and from head- eye movements such as seen in the gazing, foraging, and defensive behav- 
Sorex fumeus

A

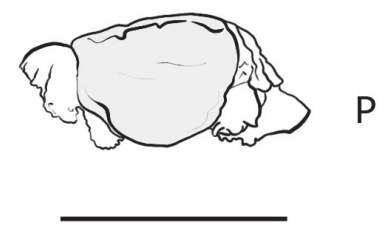

Scalopus aquaticus

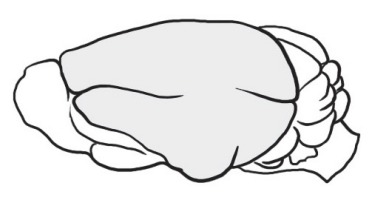

Solenodon paradoxus

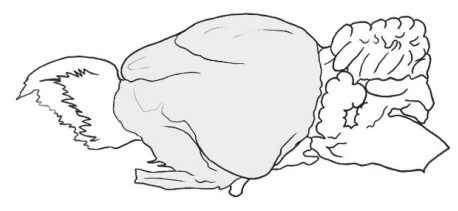

Blarina brevicauda

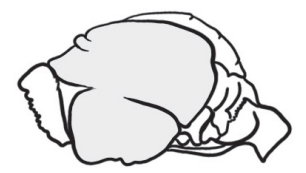

Erinaceous europeus

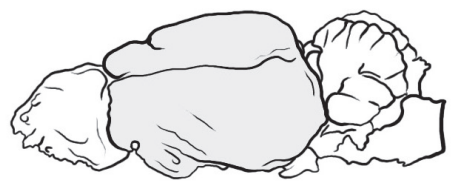

Nesophontes major

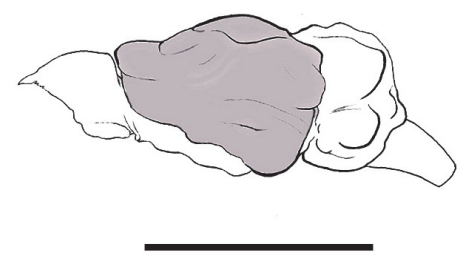

Condylura cristata

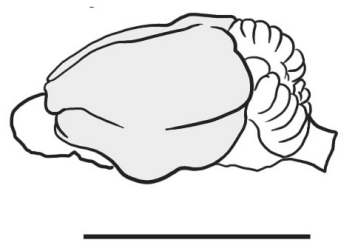

Tenrec ecaudatus

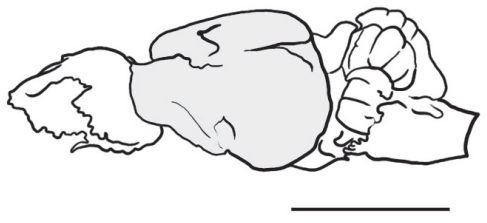

Rattus norvegicus

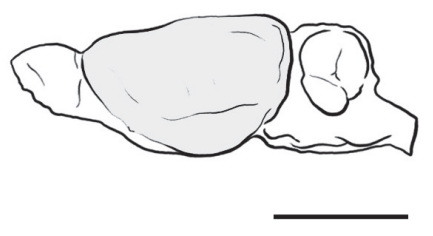

FIGURE 12. Idealized brain reconstruction of Nesophontes major compared to other insectivoran-mammals, plus the Norway rat Rattus norvegicus. Sorex, Blarina, Condylura, Scalopus, and Rattus specimens were redrawn and modified from specimens in the Comparative Brain Collection at www.brainmuseum.org and Sarko et al. (2009). Erinaceous, Tenrec, and Solenodon were drawn from Stephen and Andy (1982). A and $\mathbf{P}$ stand for anterior and posterior. Scale bar $=1 \mathrm{~cm}$.

ior of Solenodon and Tenrec described by Eisenberg and Gould (1966) and Stephen and Andy (1982). Nesophontes probably had a long, mobile nasal snout with movable vibrissae or whiskers for foraging and the detection of prey similar to that of Solenodon, Hemicentetes and Tenrec, (True, 1886; Beddard, 1901; Allen, 1910; McDowell, 1958; Eisenberg and Gould, 1966; Wible, 2008). Altogether, most of these characteristics suggest that Nesophontes was most likely nocturnal, terrestrial, and probably a very specialized fossorial insectivoran. Moreover, the scars for the levator labii and erector vibrissarum in the maxilla of $\mathrm{NesO}-$ phontes, as in Solenodon (Allen, 1910; Jolicoeur et al., 1984; Sánchez-Villagra and Asher, 2002; Catania, 2005), suggest the use of vibrissae and mobile snouts in similar foraging and defensive behavior.

With the available endocasts it is not possible to infer whether Nesophontes used echolocation as reported for many lipotyphlans (Eisenberg and Gould, 1966; Orliac et al., 2012). Pathway connec- tions between superior colliculi and optic layers have been supported by Lee and Hall (1995). The relationship of visual-motor guidance involved in eye/head movement and the development of superior colliculi has been compared to those of fructiverous megabats, monkeys, and in echolocating mammals such as microbats and several shrews (Valentine et al., 2002; Silcox et al., 2011; Orliac et al., 2012). Alternatively, the trace of these structures on the endocasts of Nesophontes indicates poor development of its cerebral hemispheres (Kielan-Jaworowska et al., 2004; May, 2005), but not vision directly.

\section{Study Limitations}

The study presented here is limited by several factors, but most especially by preservation. The detail of the natural endocasts in this case depended on taphonomic processes, such as the fragmentation of the fossil crania, and the extent to which the braincase filled with sediment during 
burial. Complete compaction and hardening of finer clay inside the braincase would have resulted in better casts. Most of the natural endocranial casts studied were incomplete.

The study of the digital endocasts reported here is also limited by their relatively low resolution, a result of equipment selection and the small size and density of Nesophontes crania. Specimens were scanned and reconstructed from data acquired with a multidetector CT (MDCT) designed for humans, and not from micro-computed tomography (micro-CT). Micro-CT would allow for the rendering of higher resolution casts due to their acquisition of thinner slices (Abel et al., 2012). Additional scanning with such better technology is already part of a future study to understand the morphological variation of the genus. The volume rendering of Nesophontes endocasts are based on an "air-structure" algorithm designed to visualize air-filled cavities, which allows only for the reconstruction of negative impressions inside the braincase, and can help approximate the original brain structures (Abel et al., 2012). The absence of a feature on these endocasts cannot be considered as indication of the nonexistence of such a feature. All scanned specimens are included in Figure 7 for further comparison.

Nevertheless, despite the limitations, studies have shown that the digital and natural endocranial casts give a fairly accurate approximation of brain morphology (Edinger, 1949; Macrini et al., 2007b; Abel et al., 2012). The measurements and morphology recorded from Nesophontes's digital endocasts are congruent with those observed in the natural endocasts. Together, the two types of endocasts provide an unreported approximation of Nesophontes endocranial characteristics that are comparable to other extinct and extant taxa (Macrini et al., 2007a; Jerison, 2009; Abel et al., 2012)(Figures 7, 11, and 12).

\section{Conclusions}

The endocranial morphology of Nesophontes spp. reported here allows for a generalized inference of their ecology, behavior, diversity, and evolution. Additionally, it adds data to the developing corpus of evidence on mammalian brain evolution in extant and extinct forms (see cited literature in Bauchot and Stephan, 1967; Macrini et al., 2007a; Jerison, 2009; Rowe et al., 2011).

Brain characters observed in the natural and digital endocranial casts of Nesophontes suggested that this taxon was probably as specialized as the lipotyphlan Solenodon, with well-developed olfactory, auditory, and tactile senses that are most likely associated to nocturnal habits. Nesophontes was most likely terrestrial and fossorial. Like Solenodon and Tenrec, it had a sensible mobile snout (proboscis) used as tactile and olfactory to sense its environment. However, with the present data, it is not possible to deduce whether Nesophontes used echolocation, like it has been documented for Solenodon and other insectivoran-grade mammals (Eisenberg and Gould, 1966; Orliac et al., 2012).

The endocranial morphology of Nesophontes is most similar to that of other lipotyphlans, especially Solenodon, rather than erinaceids, soricids, and talpids (Figure 12). Encephalization quotients and general brain characteristics superficially support its phylogenetic association to basal insectivoran-grade mammals and lipotyphlans. Foremost, the morphological similarities of Nesophontes to species that are considered "primitive" within the clade such as Solenodon and ericnaceids incipiently support its position among other basal Holartic insectivorans, where Nesophontes seems to be a sister taxon of a Solenodon-talpid-soricid clade (Robles et al., 2004; Asher et al., 2005; Douady and Douzery, 2009).

The future availability of better preserved natural endocasts and the scanning of the remaining Antillean taxa can help confirm these initial conclusions about nesophontid brain morphology and derived characteristics. Furthermore, such data can help detect interspecific differences between all other Antillean Nesophontes and help resolve the slight differences detected between the natural and digital endocasts. Such data can help reconstruct the relationship of Nesophontidae to other mammals, especially to other extinct insectivorans, and their evolution in the Antilles.

\section{ACKNOWLEDGEMENTS}

I am greatly indebted to my friend and colleague A. Tejedor for all his guidance with Nesophontes during the past decade. I thank T.E. Macrini from St. Mary's University (San Antonio, Texas) and R. Asher from the American Museum of Natural History, New York (AMNH) for providing necessary literature and for guidance and superb comments. Thanks are due to R. Viera, C. Santana, and L.P. Orozco for field logistics and support. I also thank fellow CT technologists W. Gilmour, R.V. Rodriguez, and K. Davis for their guidance during the scanning and reconstruction processes. Foremost, I thank T.E. Macrini, L.S. Collins (Florida International University), T. 
Castaño, J. Álvarez Licourt, and several anonymous referees for reviewing multiple versions of this article and providing useful suggestions.

\section{REFERENCES}

Abel, R.L., Laurini, C.R., and Richter, M. 2012. A paleobiologist's guide to 'virtual' micro-CT preparation. Palaeontologia Electronica, 15(2); 6T, 17p; palaeoelectronica.org/content/issue-2-2012-technical-articles/233-micro-ct-workflow

Allen, G.M. 1910. Solenodon paradoxus. Memoirs of the Museum of Comparative Zoology, Harvard College, 40:1-54.

Allen, G.M. 1942. Extinct and Vanishing Mammals of the Western Hemisphere with the Marine Species of All the Oceans. American Committee for International Wild Life Protection Special Publication No.11. The Intelligent Printing Co., Pennsylvania.

Anthony, H.E. 1916. Preliminary diagnosis of an apparently new family of insectivores.

Bulletin of the American Museum of Natural History, 35(41):725-729.

Anthony, H.E. 1918. The indigenous land mammals of Porto Rico, living and extinct. Memoirs American Museum Natural History, Vol. 2, Series 2:333-435.

Asher, R.J. 2001. Cranial anatomy in tenrecid insectivorans: character evolution across competing phylogenies. American Museum Novitates, 3352:1-54.

Asher, R.J., Novacek, M.J., and Geisler, J.H. 2003. Relationships of endemic African mammals and their fossil relatives based on morphological and molecular evidence. Journal of Mammalian Evolution, 10:131194.

Asher, R.J., Emry, R.J., and McKenna, M. 2005. New material of Centetodon (Mammalia, Lipotyphla) and the importance of (missing) DNA sequences in systematic paleontology. Journal of Vertebrate Paleontology, 25:911-923.

Asher, R.J. and Helgen, K.M. 2010. Nomenclature and placental mammal phylogeny. BMC Evolutionary Biology, 10:102.

Ashwell, K. 2010. The Neurobiology of Australian Marsupials. Cambridge University Press, Cambridge.

Barton, R.A., Purvis, A., and Harvey, P.H. 1995. Evolutionary radiation of visual and olfactory brain systems in primates, bats, and insectivores. Philosophic Transactions of the Royal Society of London (B), 348:381- 392.

Bauchot, R. and Stephan, H. 1967. Encéphales et moulages endocraniens de quelques insectivores et primates actuels. In: Problemes actuels in paleontologie (Évolution des Vertébrés): Colloques Interanationaux de Centre National de la Recherche Scientifique. Paris, France, 6-11 June 1966. Editions du Centre National de la Recherché Scientifique, 163:575-586.
Beddard, F.E. 1901. Some notes upon the brain and other structures of Centetes. Novitates Zoological, 8:7-92.

Butler, A.B. and Hodos, W. 2005. Comparative Vertebrate Neuroanatomy: Evolution and Adaptation (second edition). Wiley-Liss, New York.

Catania, K.C. 2005. Evolution of sensory specializations in insectivores. The Anatomical Record Part a, 287a:1038-1050.

Comparative Brain Collection at www.brainmuseum.org accessed on 10-12 January 2012.

Clark, W.E.L.G. 1932. The brain of the Insectivora. Proceedings of the Zoological Society of London, 1932:975-1013.

Clark, W.E.L.G. 1959. The Antecedents of Man. Edinburgh University Press, Edinburgh.

DigiMorph: Digital Morphology collections of the University of Texas at www.digimorph.org/ accessed on 1012 January 2012.

Douady, C.J. and Douzery, E.J.P. 2009. Hedgehogs, shrews, moles, and Solenodons (Eulipothphla) p. 495-498. In Hedges, S.B. and Kumar, S. (eds.), The Timetree of Life, Oxford University Press, Cambridge.

Edinger, T. 1949. Paleoneurology versus comparative brain anatomy. Confinia Neurologica, 9:5-20.

Edinger, T. 1964. Midbrain exposure and overlap in mammals. American Zoologist, 4:5-19.

Eisenberg, J.F. 1981. The Mammalian Radiations. University of Chicago Press, Chicago.

Eisenberg, J.F. and Gould, E. 1966. The behavior of Solenodon paradoxus in captivity with comments on the behavior of other insectivores. Zoologica, 51:4958.

Gill, T. 1872. Arrangements of the families of Mammals with analytical tables. Smithsonian Miscellaneous Collections, 11:1-98.

Gould, S.J. and Garwood, R.A. 1969. Levels of integration in mammalian dentitions: An analysis of correlations in Nesophontes micrus (Insectivora) and Oryzomys couesi (Rodentia). Evolution, 23(2):276300.

Gundlach, J. 1877. Contribución a la mamología Cubana. Imprenta de G. Montiel, Co. Habana.

Hutterer, R. 2005. Order Soricomorpha, p. 222-223. In Wilson, D.E. and Reeder, D.M. (eds.), Mammal Species of the World, third edition. John Hopkins University Press, Cambridge.

Jerison, H.J. 1973. Evolution of Brain and Intelligence. Academic Press, New York.

Jerison, H.J. 2009. How can fossils tell us about the evolution of the neocortex? p. 497-508. In Kaas, J.H. (ed.), Evolutionary Neuroscience. Elsevier, Amsterdam.

Jolicoeur, P., Pirlot, P., Baron, G., and Stephan, H. 1984. Brain structure and correlation patterns in Insectivora, Chiroptera, and Primates. Systematic Zoology, 33:14-29. 
Kielan-Jaworowska, Z. 1984. Evolution of the therian mammals in the Late Cretaceous of Asia. Part VI. Endocranial casts of eutherian mammals. Palaeontologia Polonica, 46:157-171.

Kielan-Jaworowska, Z. and Lancaster, T.E. 2004. A new reconstruction of multituberculate endocranial casts and encephalization quotient of Kryptobaatar. Acta Palaeontologica Polonica, 49:177-188.

Kielan-Jaworowska, Z., Cifelli, R.L., and Luo, Z-X. 2004. Mammals from the Age of Dinosaurs: Origins, Evolution and Structure. Columbia University Press, New York.

Leche, W. 1907. Zur Entwicklungsgeschichte des Zahnsystems der Säugetiere. Zweiter Teil: Phylogenie. Zweites Heft: Die Familien der Centetidae, Solenodontidae, und Chrysochloridae. Zoologica, 49:1-157.

Lee, P. and Hall, W.C. 1995. Interlaminar connections of the superior colliculus in the tree shrew. II: Projections from the superficial grey to the optic layer. Visual Neuroscience, 12:573-588.

Ligabue-Braun, R., Verli, H., and Carlini, C.R. 2012. Venomous mammals: A review. Toxicon, 59: 680-695.

Luo, Z.X., Crompton, A.W., and Sun, A.L. 2001. A new mammaliaform from the early Jurassic and evolution of mammalian characteristics. Science, 292:15351540.

Macrini, T.E. 2012. Comparative morphology of the internal nasal skeleton of adult marsupials based on x-ray computed tomography. Bulletin of the American Museum of Natural History, 365:91pp.

Macrini, T.E., Rougier, G.W., and Rowe, T. 2007a. Description of a cranial endocast from the fossil mammal Vincelestes neuquenianus (Theriiformes) and its relevance to the evolution of endocranial characters in therians. Anatomical Record, 290:875892.

Macrini, T.E., Rowe, T., and Archer, M. 2006. Description of a cranial endocast from a fossil platypus, Obdurodon dicksoni (Monotremata, Ornithorynchidae), and the relevance of endocranial characters to monotreme monophyly. Journal of Morphology, 267:10001015.

Macrini, T.E., Rowe, T., and VandeBerg, J.L. 2007b. Cranial endocasts from growth series of Monodelphis domestica (Didelphidae, Marsupialia): A study of individual and ontogenic variation. Journal of Morphology, 268:844-865.

Martin, R.D. 1981. Relative brain size and basal metabolic rate in terrestrial vertebrates. Nature, 293:5360.

MacFadden, B.J. 1980. Rafting mammals or drifting islands? Biogeography of the Greater Antillean insectivores Nesophontes and Solenodon. Journal of Biogeography, 7:11-22.

MacPhee, R.D.E. 1981. Auditory regions of primate and eutherian insectivore: morphology, ontogeny, and character analysis. Contribution to Primatology, 18:1282.
MacPhee, R.D.E. 2005. "First" appearance in the Cenozoic land-mammal record of the Greater Antilles: significance and comparisons with South American and Antarctic records. Journal of Biogeography, 32:551564.

MacPhee, R.D.E. and Grimaldi, D.A. 1996. Mammal bones in Dominican amber. Nature, 380:489-490.

MacPhee, R.D.E., Flemming, C., and Lunde, D.P. 1999. "Last occurrence" of the Antillean insectivoran Nesophontes: New radiometric dates and their interpretation. American Museum Novitates, 3261:1-21.

May, P.J. 2005. The mammalian superior colliculus laminar structure and connections. Progress in Brain Research, 151:321-378.

McDowell, S.B. 1958. The Greater Antillean insectivores. Bulletin of the American Museum of Natural History, 115:113-214.

McFarlane, D.A. 1999. A note on dimorphism in Nesophontes edithae (Mammalia: Insectivora), an extinct island-shrew from Puerto Rico. Caribbean Journal of Science, 35:142-143.

Morgan, G.S. and Woods, C.A. 1986. Extinction and zoogeography of West Indian land mammals. Biological Journal of the Linnean Society, 28:167-203.

Nieuwenhuys, N., ten Donkelaar H.J., and Nicholson C. 1998. The Central Nervous System of Vertebrates. Springer, New York.

Orliac M.J., Argot, C., and Gilissen, E. 2012. Digital Cranial Endocast of Hyopsodus (Mammalia, "Condylarthra"): A Case of Paleogene Terrestrial Echolocation? PLoS ONE 7(2):e30000. doi:10.1371/ journal.pone. 0030000 .

Pillay, P. and Manger, P.R. 2007. Order specific quantitative patterns of cortical gyrification. European Journal of Neuroscience, 25:2705-2712.

Radinsky, L.B. 1968. A new approach to mammalian cranial analysis, illustrated by examples of prosimian primates. Journal of Morphology, 124:167-180.

Roca, A.L., Bar-Gal, G.K., Eizirik, E., Helgen, K.M., Maria, R., Springer, M.S., O'Brian, S.I., and Murphy, W.J. 2004. Mesozoic Origin for West Indian Insectivores. Nature, 429:649-651.

Rowe, T. B. 1996. Coevolution of the mammalian middle ear and neocortex. Science, 273: 651-654.

Rowe, T.B., Macrini, T.E., and Luo, Z.X. 2011. Fossil evidence on origin of the mammalian brain. Science, 332:955-957.

Sánchez-Villagra, M.R. and Asher, R.J. 2002. Craniosensory adaptations in small faunivorous semiaquatic mammals, with special reference to olfaction and the trigeminal system. Mammalia, 66:93-109.

Sarko, Diana K., K. C. Catania, D. B. Leitch, J. H. Kaas, and S. Herculano-Houzel. 2009. Cellular scaling rules in insectivore brains. Frontiers in Neuroanatomy, 3: 1-8. doi: 10.3389/neuro.05.008.2009

Scalia, F., and Winans, S. 1975. The differential projections of the olfactory bulb and accessory olfactory bulbs in mammals. Journal of Comparative Neurology, 161:31-56. 
Silcox, M.T., Dalmyn, C.K., Hrenchuk, A., Boch, J.L., Boyer, D.M., and Houde, P. 2011. Endocranial morphology of Labidolemur kayi (Apatemyidae, Apotheria) and its relevance to the study of brain evolution in Euarchontoglires. Journal of Vertebrate Paleontology, 31:1314-1325.

Silva-Taboada, G., Suárez Duque, W., and Díaz Franco, S. 2007. Compendio de los Mamíferos Terrestres Autóctonos de Cuba Vivientes y Extinguidos. Ediciones Boloña, La Habana.

Stephan, H. and Andy, O.J. 1982. General brain characteristics and septal areas of the Insectivores, p. 525564. In Schnitzlein, H.N. (ed.), Comparative Correlative Neuroanatomy of the Vertebrate Telencephalon. MacMillan Publication Co. Inc. London.

Stephan, H., Baron, G., and Frahm, H.D. 1991. Comparative Brain Research in Mammals. Volume 1: Insectivora. Springer Verlag, New York.

Thewissen, J. G. M., and P. D. Gingerich 1989. Skull and endocranial cast of Eoryctes melanus, A new Palaeoryctid (Mammalia: Insectivora) from the Early Eocene of Western North America. Journal of Vertebrate Paleontology, 9(4): 459-470.
True, F.W. 1886. The Almiquí. Science, 8:282.

Valentine, D.E., Sinha, S.R., and Moss, C.F. 2002. Orienting responses and vocalizations produced by microstimulation in the superior colliculus of the echolocating bat Eptesicus fuscus. Journal of Comparative Physiology, 188:89-108.

Walker, E.P., Warkick, F., Hamlet, S.E., Lange, K.I., Davis, M.A., Uible, H.E., and Wright. P.F. 1975. Mammals of the World (third edition) Volume 1. John Hopkins University Press, Baltimore.

Whidden, H.P. and Asher, R.J. 2001. The origin of the Greater Antillean insectivorans, p. 237-257. In Woods, C.H., and Sergile, F.E. (eds.), Biogeography of the West Indies: Patterns and Perspectives second edition. CRC Press, Boca Raton.

Wible, J.R. 2008. On the cranial osteology of the Hispaniolan Solenodon, Solenodon paradoxus Brandt, 1893 (Mammalia, Lipotyphla, Solenodontidae). Annals of the Carnegie Museum, 73:117-196. 


\section{APPENDIX}

List of endocranial character states from Nesophontes (several characters were adopted and modified from Macrini et al., 2007a).

\section{Character 1}

Olfactory bulb cast percent composition: $6 \%$ or greater $=0$; less than $6 \%=1$

Nesophontes olfactory lobe percent composition from total brain volume ranges from $20-25 \%$ (score of $=0$ ). Nesophontes approaches the overall percent composition of Tenrec and Hemicentetes the most (Stephan and Andy, 1982). That of Solenodon is $17.95 \%$, and from other insectivorans reported by Stephan and Andy (1982).

\section{Character 2}

Width to length ratio of olfactory lobes: longer than wide (aspect ratio $<0.9$ ) $=0$; wider than long (aspect ratio $>1.1)=1$; equivalent (aspect ratio between 0.9 and 1.1) $=2$. Nesophontes sp. scores $=2$.

\section{Character 3}

Accessory olfactory bulb casts: absent $=0$; present=1.

Accessory olfactory bulbs are not always present in the endocranial casts of extinct or extant mammals (Bauchot and Stephan, 1967; Macrini et al., 2007a). Stephan and Andy (1982) reported "no accessory bulbs" on the olfactory lobes of Solenodon paradoxus. This state is scored $=0$ here, was considered unique in Solenodon in comparison to other insectivoran-grade mammals such as Erinaceus, Sorex, Tenrec, Hemicentetes, and Microgale. It also scores $=0$ in Nesophontes.

Such accessory bulbs apparently receive nerve fibers (or projections) from the vomero-nasal organ and are involved in the detection of pheromones (Nieuwenhuys et al., 1998; Macrini et al., 2007a).

\section{Character 4}

Olfactory bulb tracts (or peduncles): not visible on endocasts $=0$; visible on endocasts $=1$. Nesophontes sp. scores $=1$.

\section{Character 5}

Circular fissure: Absent or shallow on endocast $=$ 0 ; marked or deep on endocast $=1$. Nesophontes sp. scores $=1$.

\section{Character 6}

Surface of cerebral hemisphere endocasts: lissencephalic or smooth $=0$; gyrencephalic or convoluted $=1$. Nesophontes sp. scores $=0$.

\section{Character 7}

Rhinal fissure seen on endocast: not visible or absent $=0$; visible or present on endocast $=1$. Nesophontes sp. scores $=1$.

\section{Character 8}

Lateral extent of the cerebral hemisphere cast: medial to or even with the parafloccular casts $=0$; clearly extending laterally beyond the parafloccular casts $=1$. Nesophontes sp. scores $=1$.

\section{Character 9}

Cast of the superior sagittal sinus: not visible on dorsal surface of the endocast $=0$; visible $=1$.

Nesophontes sp. scores $=1$. Note: this character is often not visible on endocasts if located deep or thickly covered by the meninges (Macrini et al., 2007a).

\section{Character 10}

Ossified falx cerebri: absent $=0$; present $=1$. Nesophontes sp. scores $=0$.

\section{Character 11}

Ossified tentorium: absent $=0$; present posteromedially $=1$; present laterally $=2$; completely present $=3$. These stages are explained in Macrini et al. (2007a). Nesophontes sp. scores $=0$.

\section{Character 12}

Wide gap between the neocortex and cerebellum casts: absent $=0$; present $=1$. Nesophontes sp. scores $=$ ? But probably $=1$.

This character is problematic in Nesophontes because there are slight discrepancies between the natural and digital endocasts. Natural endocasts show a slight indentation or gap between the neocortex and cerebellum that seems very shallow in the digital endocast. However, imprints within this region of the osseous braincase support a shallow gap between these structures.

\section{Character 13}

Extent of the tectum and colliculi casts: below $=0$; at the same level of the vermis $=1$; above $=2$. Nesophontes sp. scores $=1$. 


\section{Character 14}

Extent of vermis cerebelli: cast of vermis extending to or even with the parafloccular casts $=0$; vermis remains behind the parafloccular casts $=1$; vermis extends beyond parafloccular casts $=2$. Nesophontes sp. scores $=2$.

\section{Character 15}

Extent of cerebellar hemisphere casts not visible on endocasts $=0$; visible $=1$. Nesophontes sp. scores $=1$.

\section{Character 16}

Shape of parafloccular casts: cone-shaped $=0$; broad and round $=1$; ovoid, large, and oriented posterolaterally $=2$; long and cylindrical $=3$. Nesophontes sp. scores $=2$.

\section{Character 17}

Prootic canal visible on squamosal bone of the skull (character taken from Wible, 2008): absent = 0 ; present $=1$. Both Cuban Nesophontes score $=$ 1. The orbitotemporal grove may be associated with this structure in Nesophontes, as it is in Solenodon (ecps: Wible, 2008: figure 21, p. 349).

Prootic canals are not known from any other placental mammal. They are reported from Mesozoic mammaliaforms and several Cenozoic eutherians, monotremes, and some marsupials. See Wible (2008) for discussion of this character and literature.

\section{Character 18}

Canal for carotid arteries relative to the hypophysis: posterolaterally positioned $=0$; anterolaterally positioned $=1$. Nesophontes sp. scores $=0$.

\section{Character 19}

Orbitotemporal groove not visible over perotic portion of squamosal cast $=0$; visible on endocast $=1$. Nesophontes sp. scores $=1$. This groove can represent the cast of a meningeal vessel.

\section{Character 20}

Nasoturbinal foramina located inferior to ectoturbinal foramina II not on a depression $=0$; on depression $=1$. Nesophontes sp. scores $=1$. 